\title{
DISSEMINAÇÃO DA COVID-19 NAS FAIXAS DE FRONTEIRA TERRESTRE E LITORÂNEA DO BRASIL'
}

\author{
Liria Nagamine ${ }^{2}$ \\ Gustavo Ferreira ${ }^{3}$ \\ Caroline Krüger $^{4}$ \\ Rosa Moura ${ }^{5}$
}

\begin{abstract}
Atualmente, o Sars-COV-2 se encontra disseminado por uma vasta área geográfica no mundo. A trajetória da pandemia após cruzar as fronteiras do território brasileiro (terrestre e litorânea), acompanhada de uma avaliação das medidas adotadas para sua contenção e os principais conflitos observados e apresentados no presente estudo, cumpre o objetivo de apontar questões atuais e futuras de políticas públicas para 0 enfrentamento da pandemia nas fronteiras brasileiras. Os resultados das análises realizadas demonstram que as áreas de maior concentração e adensamento populacional urbanos foram as mais afetadas pela contaminação do vírus. No entanto, a Covid-19 não poupou municípios menores, o que se observa pelo seu alastramento no território seguindo os caminhos da mobilidade rodoviária, fluvial e aérea no interior do Brasil. Sobre seu reflexo na área de fronteira, observa-se tanto um conflito interfederativo, com um quadro de descompasso entre medidas do governo federal e unidades subnacionais, quanto a inexistência de diálogos e acordos com os países vizinhos. Como sugestões, apontam-se a criação de instrumentos, protocolos, medidas e mecanismos para o enfrentamento da crise da pandemia da Covid-19 em áreas de fronteira terrestre e litorânea do Brasil.
\end{abstract}

Palavras-chave: pandemia; Covid-19; fronteira terrestre; fronteira litorânea; medidas de contenção.

\section{THE SPREAD OF COVID-19 IN THE BRAZILIAN TERRESTRIAL AND COASTAL BORDER AREAS}

Nowadays Sars-COV-2 is spread over a vast geographical area in the world. The trajectory of the pandemic after crossing the borders of the Brazilian territory (land and coastal), accompanied by an assessment of the measures adopted for its containment and the main conflicts observed and presented in the present study, fulfill the objective of pointing out current and future public policy issues to tackle the pandemic on Brazilian borders. The results of the analyzes carried out demonstrate that the areas with the highest concentration and urban population density were the most affected by virus contamination. However, Covid-19 did not spare smaller municipalities, which is observed by its spread in the territory following the paths of road, river and air mobility in the interior of Brazil. Regarding its reflection in the border area, there is both an inter-federative conflict, with a picture of mismatch between measures of the federal government and subnational units, and the absence of dialogues and agreements with neighboring countries. As suggestions, we point out the creation of instruments, protocols, measures and mechanisms to face the Covid-19 pandemic crisis in land and coastal borderline areas of Brazil.

Keywords: pandemic; Covid-19; borderland; coastal border; containment measures.

1. Este artigo é parte dos resultados de uma pesquisa que vem sendo desenvolvida no âmbito da Diretoria de Estudos e Políticas Regionais, Urbanas e Ambientais (Dirur) do Ipea sobre a pandemia da Covid-19 e as fronteiras.

2. Pesquisadora na Dirur/lpea. E-mail: <liria.nagamine@ipea.gov.br>. Orcid: <https://orcid.org/0000-0003-2440-7510>.

3. Pesquisador na Dirur/lpea. E-mail: <gustavo.ferreira@ipea.gov.br>. Orcid:<https://orcid.org/0000-0001-7841-2767>.

4. Pesquisadora na Dirur//pea. E-mail:<caroline.guimaraes@ipea.gov.br>. Orcid: <http://orcid.org/0000-0002-6368-9138>

5. Profissional sênior na Dirur//pea. E-mail: <rosa.silva@ipea.gov.br>. Orcid: <https://orcid.org/0000-0003-1702-0617>. 


\section{DIFUSIÓN DE LA COVID-19 EN LAS FRONTERIZAS TERRESTRES Y COSTERAS DE BRASIL}

Actualmente la Sars-COV-2 se extiende sobre una vasta área geográfica en el mundo. La trayectoria de la pandemia después de cruzar las fronteras del territorio brasileño (terrestre y costero), acompañada de una evaluación de las medidas adoptadas para su contención y los principales conflictos observados y presentados en el presente estudio, cumplen el objetivo de señalar los problemas de política pública actuales y futuros para hacer frente a la pandemia en las fronteras brasileñas. Los resultados de los análisis realizados demuestran que las áreas con mayor concentración y densidad de población urbana fueron las más afectadas por la contaminación viral. Sin embargo, el Covid-19 no perdonó a los municipios más pequeños, lo que se observa por su extensión en el territorio siguiendo los caminos de la movilidad por carretera, río y aire en el interior de Brasil. En cuanto a su reflejo en el área fronteriza, existe un conflicto interfederativo, con un desajuste entre las medidas del gobierno federal y las unidades subnacionales, y la ausencia de diálogos y acuerdos con los países vecinos. Como sugerencias, señalamos la creación de instrumentos, protocolos, medidas y mecanismos para enfrentar la crisis pandémica de Covid-19 en las zonas fronterizas terrestres y costeras de Brasil.

Palabras clave: pandemia; Covid-19; frontera terrestre; frontera costera; medidas de contención. JEL: R38; R58.

DOI: http://dx.doi.org/10.38116/rtm23art8

Data de envio do artigo: 17/6/2020; Data de aceite: 26/8/2020.

\section{INTRODUÇÃO}

O novo coronavírus (Sars ${ }^{6}-\mathrm{COV}-2$ ), causador de infecções respiratórias caracterizadas pela alta capacidade de contaminação e efeitos letais, teve a China como primeiro epicentro de transmissão do vírus no final de 2019. Ainda nos primeiros meses de 2020, se proliferou rapidamente pela Ásia, Europa, América e outras partes do mundo. Em 28 de fevereiro de 2020, a Organização Mundial da Saúde (OMS) acionou o alerta de risco de alto para muito alto, quando a doença já atingia mais de cinquenta nações. Os vetores eram as pessoas em circulação, o que levou a uma corrida global por medidas de triagem e fechamento de fronteiras terrestres (postos de controle), marítimas (portos) e aéreas (aeroportos), isolamento de grupos de alto risco, distanciamento social e diagnósticos e testagem em massa.

Desde então, os países têm sido acionados pela OMS a "superar as divisóes políticas e as fronteiras geográficas para aumentar o apoio a uma resposta proporcional a essa crise sem precedentes", que se insere náo só como uma grave ameaça à saúde pública, mas ao bem-estar social e econômico das naçóes.7 Com medidas de contenção insuficientes, ausência de tratamentos eficazes e 
disponibilidade de uma vacina, e com o vírus apresentando mutaçóes e novas ondas de surto surgindo em um curto espaço de tempo, ainda se enfrenta o desafio de conter a doença, principalmente diante do alto risco a que estão sujeitas as populaçóes vulneráveis, "os mais propensos a adoecer e os menos propensos a receber cuidados, como povos indígenas, pessoas de ascendência africana, pessoas em situação de pobreza nas áreas urbanas e populaçóes migrantes". ${ }^{8}$

No subcontinente sul-americano, com o Brasil superando a marca de 1 milhão de casos de Covid-19 em junho de 2020, a transmissão encontra-se generalizada. De acordo com a Organização Pan-Americana de Saúde (OPAS), a perspectiva é que o país possa, ao longo dos próximos dois anos, continuar a sofrer surtos recorrentes de Covid-19, intercalados com períodos de transmissáo limitada. Tal é o cenário que tem desafiado gestores públicos e pesquisadores em busca de soluçóes que, se por um lado emergem medidas rápidas e eficientes, por outro se destacam por se inserirem em agendas há muito defendidas de investimentos em açôes para o enfrentamento da histórica desigualdade social e econômica. Sendo assim, os conflitos que insurgem com maior relevo durante a pandemia são objetos de análise deste estudo, a partir da leitura de sua trajetória após adentrar as fronteiras brasileiras. À luz das medidas adotadas para sua contenção no Brasil, objetiva-se apontar questōes atuais e futuras de políticas públicas para o enfrentamento desse cenário pandêmico que se irrompe nas faixas de fronteira brasileiras e em suas zonas fronteiriças.

Além desta introduçáo, o artigo está estruturado em partes que abordam: i) uma leitura sobre como está se desenvolvendo o enfrentamento da pandemia a partir de uma breve abordagem dos países sul-americanos e da análise das medidas e açóes ao enfrentamento da pandemia no Brasil, desde a condução pelo governo federal até o quadro atual de atuaçóes isoladas de governos estaduais e municipais (seção 2); ii) a propagação da pandemia no Brasil, particularizando a evolução dos casos e óbitos em três recortes do território e as especificidades sobre a pandemia nas faixas de fronteira (seção 3); e iii), nas consideraçóes finais, questōes e encaminhamentos de gestão pública para as faixas de fronteira (seção 4).

\section{ENFRENTAMENTO DA PANDEMIA}

\subsection{Breve leitura dos países sul-americanos}

O Brasil se apresenta atualmente como o segundo país do mundo em número de casos e óbitos por Covid-19, sendo o epicentro da pandemia na América do Sul. Além disso, o rápido e alarmante avanço da pandemia no país tem feito os países

8. Mais informações disponíveis em: <https://www.paho.org/bra/index.php?option=com_content\&view=article\&id=6 206:paises-devem-se-preparar-para-enfrentar-surtos-recorrentes-de-covid-19-pelos-proximos-2-anos\&ltemid=812>. 
sul-americanos considerarem o Brasil uma "grande ameaça sanitária", colocando em estado de alerta autoridades dos países vizinhos, alguns mais bem-sucedidos no controle à epidemia, como Argentina, Paraguai e Uruguai (Mendonça e Molina, 2020). O governo uruguaio, apesar de acordar com o presidente brasileiro manter estreita coordenação de combate à pandemia, reforçou barreiras sanitárias em relação ao Brasil e teceu críticas à sua má administração governamental (Sperb, 2020).

Um quadro da situação dos países sul-americanos em relação à Covid-19 em 15 de junho mostra o Equador com a maior taxa de letalidade (tabela 1). A cidade portuária de Guayaquil foi foco de notícias alarmantes desde a primeira quinzena de abril, quando chocou o mundo com a retirada de centenas de corpos de residências, tendo em vista o colapso no sistema funerário e de saúde pública. O país tem enfrentado uma nova onda de letalidade desde que iniciou, em maio, a adoção de medidas de flexibilização. Entre os demais países, Peru e Chile destacam-se em segundo e terceiro lugares em relação ao número de casos. No Peru, apesar de ter sido um dos primeiros países a adotar medidas de quarentena, especialistas analisam que o alto número se explica por fatores "preexistentes da economia e sociedade peruanas" como a informalidade, baixa logística de abastecimento da população (poucos possuem geladeira), aglomeraçóes em mercados e bancos, e alto índice de pessoas por moradia (Bel, 2020). No Chile, desde 19 de junho, após registro do maior número de casos no país, o governo tem adotado medidas rígidas de controle, com penalidades em multas e prisóes. Apesar do aumento, a taxa de letalidade é uma das menores na América do Sul (Maldonado e Güell, 2020). Cabe ressaltar ainda o caso da Colômbia, que, apesar da incidência de casos relativamente menor, tem em Leticia, cidade que faz fronteira com Tabatinga, na Amazônia, o maior número de infectados. Para o ministro da Saúde daquele país, a ausência de diálogo com autoridades brasileiras é um fator da causa, haja vista o nível de contaminação que chegou o estado amazonense no Brasil. ${ }^{9}$

9. Disponível em: <https://g1.globo.com/bemestar/coronavirus/noticia/2020/06/01/coronavirus-como-cidade-nafronteira-com-brasil-se-tornou-a-lider-de-casos-de-covid-19-na-colombia.ghtml>. 
TABELA 1

América do Sul: número de casos e mortes por Covid-19 confirmados por laboratório (15 de junho de 2020)

\begin{tabular}{lccc}
\hline País & Total de mortes & Casos confirmados & Taxa de letalidade (\%) \\
\hline Brasil & 42.720 & 850.514 & 5,02 \\
Peru & 6.498 & 225.132 & 2,88 \\
Chile & 3.323 & 174.293 & 1,90 \\
Colômbia & 1.592 & 48.746 & 3,26 \\
Equador & 3.896 & 46.751 & 8,33 \\
Argentina & 819 & 30,295 & 2,70 \\
Bolívia & 585 & 17.842 & 3,27 \\
Venezuela & 24 & 2.904 & 0,82 \\
Paraguai & 11 & 1.289 & 0,85 \\
Guiana Francesa & 3 & 1.255 & 0,23 \\
Uruguai & 23 & 847 & 2,71 \\
Suriname & 3 & 187 & 1,60 \\
Guiana & 12 & 159 & 7,54 \\
\hline
\end{tabular}

Fonte: OMS, 2020, disponivel em: <https://covid19.who.int/>

Elaboração dos autores.

A falta de açóes coordenadas entre países pode ser percebida desde a fase de fechamento de fronteiras na América do Sul ocorrida em março (quadro 1). Alguns países adotaram fechar todas as fronteiras de uma vez (Argentina, Chile e Suriname); outros em um processo gradual (Bolívia, Colômbia, Equador, Paraguai e Uruguai); e em outros, ainda, esse fechamento se deu via restriçóes totais, mas em momentos diferentes (Brasil, Guiana e a Guiana Francesa). ${ }^{10}$

Pode-se afirmar que, fechadas as fronteiras, o vírus se alastrou em cada país, seguindo em cada um os caminhos civilizatórios e resultando em diferentes cenários pandêmicos, mas apresentando um comportamento em comum: manifestando a sua face mais cruel nos lugares mais distantes e periféricos, com baixa infraestrutura de atendimento médico e hospitalar, e baixa capacidade de proteçâo à infecçấo, seja pela falta de informação, seja pela vulnerabilidade socioeconômica já instalada.

10. Não há dados sobre o fechamento da fronteira com a Venezuela. As ações de fechamento foram iniciativa dos países vizinhos. 


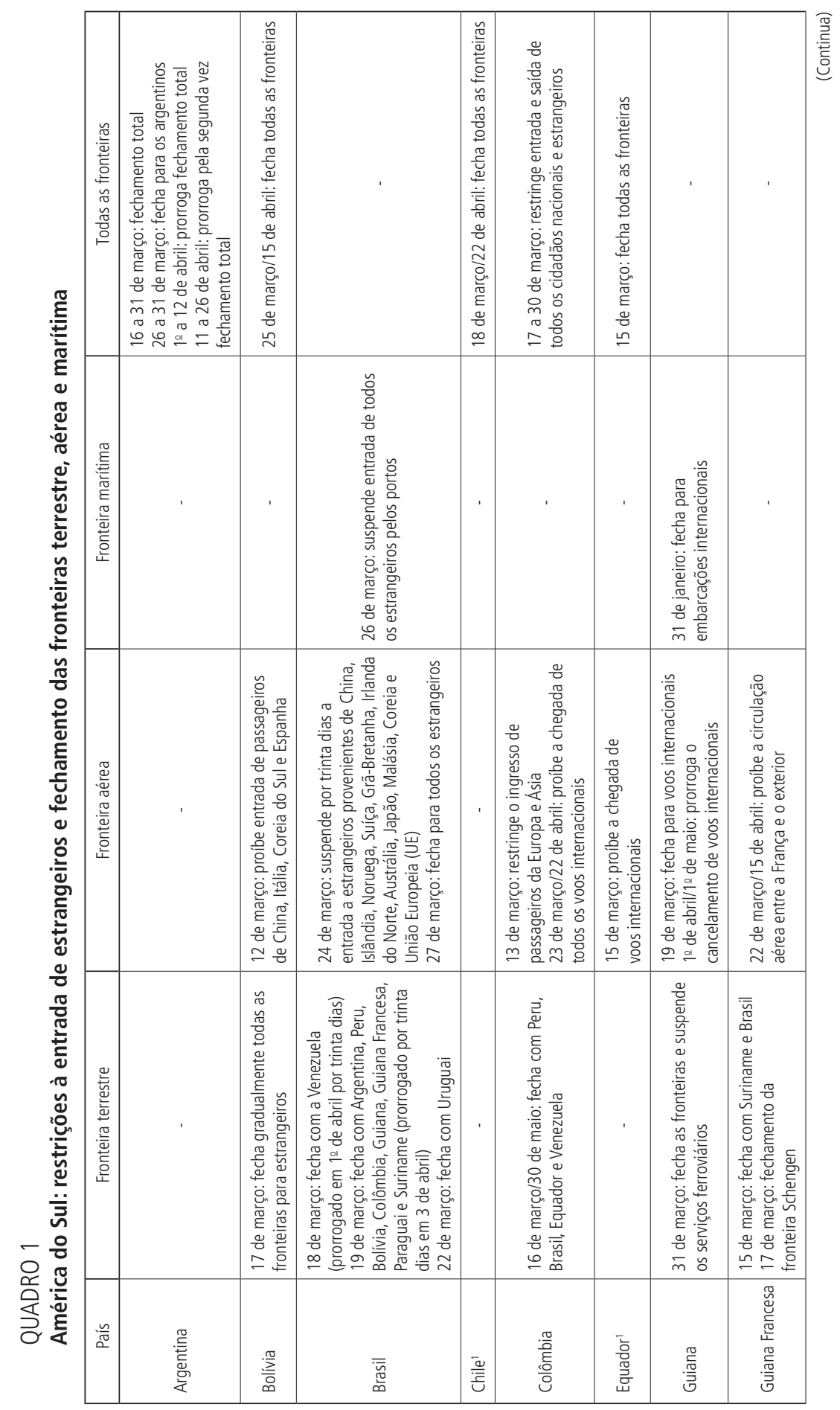




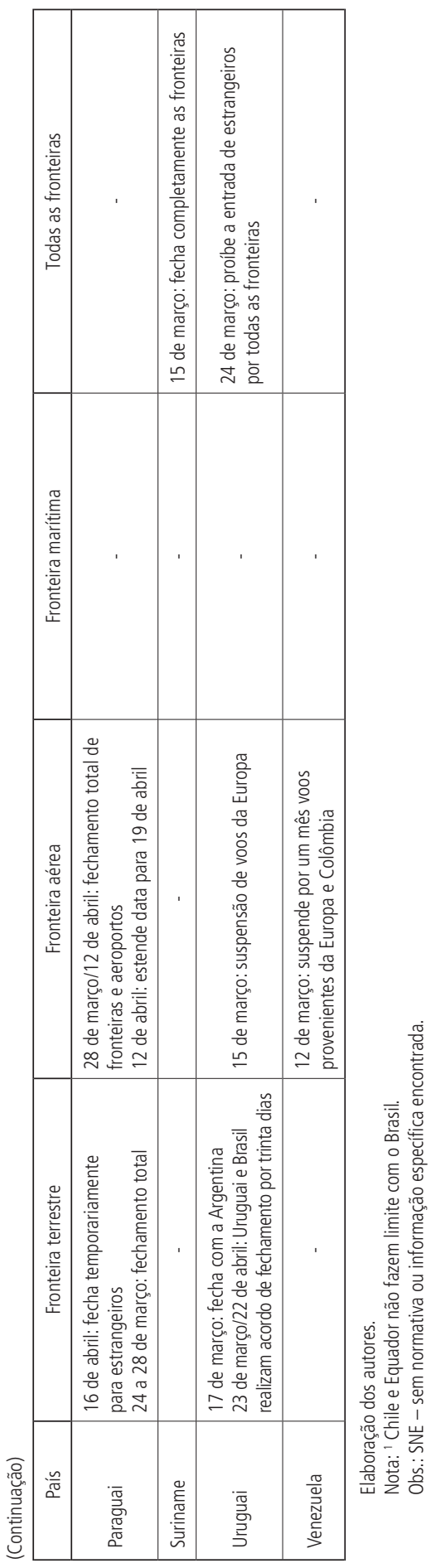




\subsection{Ações e medidas do Brasil e seus estados federados}

\subsubsection{A condução pelo governo federal}

Para uma leitura apropriada sobre a condução do governo brasileiro no enfrentamento da pandemia no país e sua repercussão sobre a fronteira, faz-se necessário compreender que "a pandemia como fato real é um problema fronteiriço" (Pêgo et al., 2020, p. 32,). Os principais aeroportos do país, situados na faixa de fronteira litorânea (FFL), foram os pontos de entrada para o desencadeamento da proliferação da Covid-19 pelo território nacional. Os momentos de fechamento gradual das fronteiras terrestres, aéreas e marítimas brasileiras, efetuados após 11 de março (ver quadro 1), quando a OMS declarou estado de pandemia internacional, caracterizaram-se como alertas efetivos à população quanto à seriedade do que estaria por vir.

Salienta-se que o governo brasileiro, por intermédio do Ministério da Saúde (MS) e seu então ministro, Luiz Henrique Mandetta, encontrava-se em boa consonância com as diretrizes emanadas pela OMS, instalando em 22 de janeiro de 2020 um Centro de Operações de Emergência (COE) e emergindo como coordenador das açóes para o enfrentamento da Covid-19 desde que foi considerada "Emergência de Saúde Pública Internacional (ESPII)", em 30 de janeiro. Importantes açóes e características dessa gestão devem ser consideradas (Pêgo et al., 2020):

- total transparência das açóes mediante a realização de entrevistas coletivas diárias sobre os acontecimentos e açóes em andamento pelo próprio ministro da Saúde, conjugadas ao lançamento de boletins epidemiológicos periódicos, tratando de questôes estruturantes ao combate e da atualização de dados situacionais;

- consciência da necessidade de açóes compartilhadas entre as instâncias federal e estadual, concretizada pela realização de reuniốes e açóes conjuntas com as secretarias da saúde de todos os entes federados, preparando e definindo, conforme recomendaçóes da OMS: infraestruturas de saúde necessárias entre postos de saúde, hospitais e laboratórios de testagem; materiais necessários às equipes de saúde e paramentação de hospitais com equipamentos para leitos de Unidade de Terapia Intensiva (UTI); capacitação dos profissionais de saúde; e divulgação e conscientização junto à população quanto aos protocolos de higienização, sanitização de ambientes, distâncias entre pessoas, entre outros;

- $\quad$ articulação dos processos administrativos e jurídicos para obtenção dos recursos e materiais necessários à execução das medidas, desde 
aquisição de materiais junto à OPAS/OMS, aquisição de mais materiais e equipamentos, repasse aos Estados, entre outros;

- busca pela utilização plena e pelo fortalecimento da rede do Sistema Único de Saúde (SUS) cuja reconhecida capilaridade e abrangência junto à população brasileira se tornaria estratégica e fundamental às ações a serem implementadas; e

- pronta elaboraçáo de um plano de contingência nacional, ao qual se seguiu a elaboração dos planos em cada estado, de tal forma que estariam estrategicamente preparados para ação junto aos municípios nos momentos em que se detectassem os sinais de alerta de contaminação comunitária.

A despeito do respeitável preparo de açóes articuladas e transparentes desenvolvidas pelo MS naquele período, verifica-se que houve falha na condução do método de detecção do vírus. Estudos realizados posteriormente evidenciam o fato de que, ao momento em que todas as fronteiras foram fechadas no Brasil, o vírus já se espalhava pelo país desde um tempo anterior ao da data da notificação do primeiro caso (em São Paulo, no dia 26 de fevereiro) (Delatorre et al., 2020), ou seja, expandia-se ao sabor dos encontros das festas de carnaval do mês de fevereiro. Dois aspectos se colocam de forma a poder explicar o atraso na detecção do primeiro caso no Brasil: i) a não adoção pela Agência Nacional de Vigilância Sanitária (Anvisa) de triagem dos passageiros por temperatura (recomendada pela OMS), por entender que não era obrigatório e de baixa efetividade; e ii) o fato de que a triagem foi realizada inicialmente apenas em relação aos passageiros provenientes da China. Somente após a identificação do primeiro caso, em viajante proveniente da Itália, ao buscar atenção hospitalar, a triagem foi estendida para os demais países, primeiramente asiáticos (21 de fevereiro) e em seguida europeus (24 de fevereiro) (Pêgo et al., 2020).

Cabe recordar que a primeira quinzena de março é marcada pela aceleração da contaminação do vírus na Europa,${ }^{11}$ quando o mundo se impactou com as imagens da devastaçáo de óbitos na Itália e depois na Espanha mediante o colapso dos leitos de UTI em hospitais. Além disso, já era evidente, a partir das experiências em países asiáticos e de estudos conduzidos pela Johns Hopkins University, que a medida mais efetiva para o controle era o distanciamento social. Tendo em vista o quadro mundial instalado e também a demora do Executivo federal em tomar medidas mais severas de enfrentamento - lembrando que todas as fronteiras só foram fechadas efetivamente no dia 27 de março -, alguns estados iniciaram a adotar açóes independentes, como o controle de temperatura nos

11. A Europa tornara-se naquele mês o epicentro do coronavírus no mundo. 
aeroportos por governos estaduais e locais (Acre, Bahia, Maranhão, Piauí, Rio de Janeiro, São Paulo e Santa Catarina), contrariando orientaçôes da Anvisa.

$\mathrm{Na}$ continuidade, outros episódios serviram para delinear o cenário de conflito interfederativo que se instalaria no país, orientado pelo posicionamento dos estados em defesa de fechar os seus territórios individualmente contra a entrada e o alastramento do vírus, ante a ausência em dialogar e articular medidas integradas pelo governo federal. Entre as medidas estaduais destacam-se as restrições à circulação de transporte estadual de passageiros rodoviários e aeroviários e a paralisação de fluxos fluviais, entre outros (Pêgo et al., 2020).

Utilizando-se da prerrogativa constitucional de autonomia administrativa de estados e municípios em áreas básicas como saúde, educação ou comércio, os governos estaduais e municipais prosseguiram em suas medidas de contenção à frente do governo federal. Primeiramente, proibiu-se a realização de eventos com alta aglomeração de pessoas e o funcionamento de escolas e clubes (definindo normas para que se mantivesse o distanciamento social por intermédio do trabalho em casa), além do funcionamento de estabelecimentos comerciais e de serviços não essenciais. Além disso, promoveu-se a diminuição da mobilidade nas cidades. Dessa forma, os governos estaduais se contrapuseram às deliberaçóes da chefia do Executivo federal, que se manteve contra o fechamento de determinados tipos de comércio e serviços, como templos religiosos ou academias de esporte (Brasil, 2020), e a favor do que definiu como distanciamento vertical (Gomes, 2020), ${ }^{12}$ além do controverso uso do medicamento denominado cloroquina. Com a questão levada a juízo no Supremo Tribunal Federal (STF), a decisão dessa corte, em 15 de abril, foi a favor dos estados e municípios, pela manutenção de suas autonomias. ${ }^{13}$

A consonância das açóes interfederativas se manteve, contudo, entre as atividades em ação ditadas pelo MS que, por sua vez, passa a atuar em clara divergência com o posicionamento presidencial, especialmente em relação ao distanciamento social (Benites e Gortázar, 2020). ${ }^{14} \mathrm{O}$ momento é delicado, pois, mesmo em dia com as recomendaçóes da OMS, e tendo conseguido cultivar o apoio dos estados, o MS atuava contra o tempo na resolução de problemas que se destacavam pela dificuldade de comprar materiais e equipamentos de saúde em situação de falta no mundo (Cancian e Uribe, 2020). ${ }^{15}$ Enquanto

12. 0 isolamento vertical, diferentemente do horizontal que implica em manter o afastamento do maior número de pessoas, trabalha com a manutenção de isolamento somente de pessoas em grupos de risco.

13. Mais informações em: <https://bit.ly/3eJ4V4A>.

14. Em 5 de abril, o jornal El País publica matéria que consolida a imagem em crescimento no país do perfil do ministro, a favor da ciência e do isolamento social (Benites e Gortázar, 2020c).

15. A aceleração do vírus nos Estados Unidos no início do mês de março provoca queda no estoque disponível de equipamentos de proteção individual (Cancian e Uribe, 2020). 
isso, complicações se avolumavam pela entrada do país na fase de aceleração descontrolada, com situação de risco nacional muito alto, segundo publicação do Centro de Operaçóes de Emergência em Saúde Pública (COE-COVID19). De acordo com boletim publicado em 3 de abril, a capacidade laboratorial do Brasil ainda era insuficiente para dar resposta a tal fase da pandemia, tendo necessidade de mais testagem, de maior número de equipes de saúde capacitadas e de leitos de UTI devidamente estruturados (COE-COVID19, 2020).

As divergências levaram à exoneração do então ministro da saúde, no dia 16 de abril, e ao arrolamento de uma série de acontecimentos que colocaram o Brasil nas manchetes internacionais pela sua excepcionalidade em relação à causa do aumento do número de casos e de óbitos: a posição negacionista conduzida pelo presidente da República em controlar o vírus, atendendo à única fórmula comprovadamente eficaz de enfrentar o problema, qual seja, o distanciamento social e, em alguns casos, o lockdown. Com Nelson Teich instituído como novo ministro da Saúde em 17 de abril, destaca-se a supressão das coletivas diárias e as reclamaçôes das secretarias de saúde estaduais sobre a falta de diálogo. Teich pediu demissão em menos de um mês, em 16 de maio de maio, também em meio a divergências com o presidente com relação ao uso da cloroquina e à não comprovação científica sobre a sua eficácia. ${ }^{16}$ Até o momento, o MS está sendo dirigido por um ministro interino, sem que se vislumbrem diretrizes de açôes que possam orientar nacionalmente os protocolos nos estados e municípios com a necessária sustentação científica. ${ }^{17}$

Sendo assim, a nítida falta de condução nacional das ações, articulada às demais instâncias, parece evidenciar outra característica em curso: não somente a tentativa de inviabilização de regras para o distanciamento social nos estados e municípios, como agora a estratégia de negação se manifesta pela tentativa de invisibilidade da realidade que se impóe a cada dia com maior intensidade. O contraditório se faz presente no atual momento, quando se torna imperativo que se divulguem regras para uma flexibilização gradual e séria: o governo encontra limites em desenvolvê-las, pois despiu-se aos poucos do corpo técnico e capacitado que estava se formando para essa função. Tal função consiste em elaborar um planejamento baseado em conteúdos científicos, transescalares e multidisciplinares, de forma a compreender o processo sistêmico com uma visão da realidade local e integrada das cidades, sendo assim capaz de realizar uma leitura

16. Estudos indicam que a cloroquina e hidroxicloroquina não possuem eficácia comprovada no tratamento da Covid-19. Mais informações disponíveis em: <https://portal.fiocruz.br/video/cloroquina-e-hidroxicloroquina-notratamento-da-covid-19>.

17. Destaca-se nesse período a polêmica tentativa de mudança no formato de comunicação de dados da Covid-19 pelo MS que passou a divulgar, em 8 de junho, somente os números diários de mortes e ocorrências, sem os resultados acumulados (Verdélio, 2020), ação que foi revertida no dia seguinte, por determinação do STF. Mais informações disponíveis em: $<$ https://www.dw.com/pt-br/moraes-manda-governo-voltar-a-divulgar-dados-totais-da-covid-19/a-53740074>. 
quali-quantitativa adequada dos dados de saúde e da infraestrutura instalada, que possa ser articulada com a necessária retomada da economia do país.

\subsubsection{A condução atual pelos governos estaduais e municipais}

O avanço da Covid-19 chegou, na última semana de análise do MS, 14 a 20 de junho, ao maior número de casos nas cidades do interior em comparação às capitais, sendo que as cidades brasileiras afetadas se encontram em diferentes estágios de contaminação. Além disso, o distanciamento social, que vem sendo aplicado há pelo menos três meses na maior parte dos municípios do país, vem sofrendo forte pressão dos segmentos econômicos, que pregam a abertura. Muitos gestores estudam e têm definido, isoladamente, açóes de flexibilização das regras de distanciamento social. O que se verifica é um verdadeiro laboratório de testagem de flexibilizaçáo no país, sendo que muitas cidades têm prematuramente permitido a reabertura de atividades econômicas, constatando, semanas depois (na maior parte duas semanas), o equívoco da decisão, dada a expansão ainda maior da propagação do vírus, elevando o número de casos e óbitos. ${ }^{18}$

Verifica-se nas medidas tomadas pelos municípios que as decisóes não se baseiam em uma visão regional, e a ser orientada pelo Estado ou decidida entre Unidades da Federação (UFs) a partir de: i) uma escala na qual se poderiam correlacionar as variáveis de número de casos e de óbitos às áreas com maior densidade de pessoas; ii) às áreas de maior vulnerabilidade social; e iii) à distância e dependência dessas áreas aos equipamentos de saúde de média e alta complexidade, entre outras, considerando as relaçóes existentes entre os municípios. Dados que demonstram um aparente controle em determinada cidade podem estar escondendo a propagação incipiente em outros pontos que se potencializam com a flexibilizaçáo, ainda mais ao se considerar o desenho de cidades conurbadas e interligadas por fortes vetores de comutação. Nesse caso, a relação é direta em grande parte das cidades localizadas na FFL, com suas aglomeraçóes urbanas e regióes metropolitanas, e é direta também entre as chamadas "cidades gêmeas" da faixa de fronteira terrestre (FFT), por sua vez divididas por orientações específicas de dois ou três países.

Medidas individuais de cidades, sem uma visão regional, são também preocupantes com relação aos municípios aparentemente isolados, em especial entre os povos da Amazônia e do Cerrado, particularmente indígenas e de comunidades tradicionais - quilombolas, ribeirinhas e de assentamentos agrários. Considerando sua vulnerabilidade, foram gravemente atingidos pela pandemia,

18. Enquanto estudo recente da Imperial College of London indica uma redução da velocidade de contágio no país, o temor observado em função de anúncios de flexibilização por cidades de todo o país tem se confirmado, tendo efeito rebote, o aumento significativo no número de casos (COE-COVID19, 2020). Mais informações disponíveis em: <https:// mrc-ide.github.io/global-Imic-reports/BRA/>. 
evidenciando desde a primeira quinzena do mês de abril a necessidade de uma ação estratégica efetiva para o enfrentamento junto à rede integrada do SUS e suas regióes de saúde. Por um lado, os pequenos centros urbanos situados relativamente próximos a essas comunidades não oferecem atendimento de média e alta complexidade; por outro, o sistema de saúde de Manaus, a centralidade principal a oferecer esses atendimentos, entrou em colapso rapidamente, pois várias cidades da regiāo dependem diretamente de sua infraestrutura hospitalar (Pêgo et al., 2020). ${ }^{19}$

As questóes expostas estimulam a ponderar sobre as graves consequências sociais e econômicas provocadas no país em função da inexistência de medidas e açôes coordenadas entre os entes federados estaduais e municipais emanadas a partir de diretrizes nacionais integradas para o combate à Covid-19. Se sob um ponto de vista tal cenário representa uma forma de desgoverno, sob outro verifica-se que esse mesmo governo se encontra articulado em levar adiante o projeto de expansão econômica territorial. É o que aponta o ministro do Tribunal de Contas da União (TCU), Vital do Rêgo, em sua relatoria do processo n ${ }^{\circ}$ TC 016.708/2020-2, ${ }^{20}$ (TCU, 2020b, p. 2), ao avaliar a ação do governo federal diante da pandemia. Descreve o ministro que o governo federal demonstra "possuir plena capacidade de organização para fins de planejamento de açôes nacionais", pois quando se trata da "retomada da economia, já estabeleceu um plano específico denominado Pró-Brasil”. Tal afirmação se faz presente no voto ao relatório elaborado e aprovado pelo TCU no dia 24 de junho, que integra o Plano Especial de Acompanhamento das Açóes de Combate à Covid-19 (PEAAC) do TCU, com o objetivo de fiscalizar e acompanhar a governança do centro de governo ${ }^{21}$ durante o enfrentamento da pandemia. Foi colocada em contraponto ao principal resultado desse que foi o primeiro relatório mensal do plano de acompanhamento "a ausência de diretrizes estratégicas, com objetivos a serem alcançados pelas açóes, bem como as prioridades eleitas" que, segundo o relatório, "pode acarretar decisões e medidas individualizadas e descoordenadas pelos diversos atores levando à inefetividade das açôes de combate à crise de Covid-19 e desperdício de recursos humanos, materiais e financeiros, com efeitos inclusive

\footnotetext{
19. Especificamente para os indígenas, o MS elaborou, por meio da Secretaria Especial de Saúde Indígena (Sesai), o Plano de Contingência Nacional para Infeccção Humana pelo novo Coronavírus (Covid-19) em Povos Indígenas e, além disso, as recomendações à Fundação Nacional do Índio (Funai) sobre medidas de restrição à entrada de pessoas nos territórios indígenas (Pêgo et al., 2020).

20. Disponivel em: <https://bit.ly/35dA6BJ>.

21. De acordo com o relatório, "integram o Centro de Governo, para o enfrentamento da pandemia do novo coronavírus, o Comitê de Crise e o Centro de Coordenação de Operações do Comitê de Crise para Supervisão e Monitoramento dos Impactos da Covid-19 (CCOP), bem como os órgãos integrantes da estrutura da Presidência da República, em especial a Casa Civil da Presidência da República e a Secretaria de Governo da Presidência da República, responsáveis pela articulação e coordenação de ações de enfrentamento à pandemia da Covid-19 e assessoramento ao presidente da República". Disponível em: <https://bit.ly/35dA6BJ>.
} 
nas diversas esferas da federação". ${ }^{22}$ Grosso modo, preocupações evidenciadas pelo relatório em função da inexistência de uma estratégia coordenada no país podem ser constatadas como realidade em curso, conforme a breve análise elaborada neste item com relação às medidas isoladas que vêm sendo tomadas pelas cidades, sem que haja uma orientação regional.

É relevante destacar, portanto, outros resultados gerais apresentados no relatório do TCU que expóem ainda mais a falta de ação do governo como grande protagonista do atual quadro de descontrole da pandemia no país. O relatório enfatiza que, ainda do ponto de vista estratégico, está ausente um modelo de gerenciamento integrado de riscos para a gestão, o que "pode levar a decisóes e açôes incoerentes, pelo Comitê de Crise e pelos demais atores envolvidos no enfrentamento à pandemia de Covid-19, levando à baixa efetividade nas açóes de prevenção e combate à doença e desperdício de recursos públicos". ${ }^{23}$ Elaborado tendo em vista quatro mecanismos de governança - estratégia, coordenaçẫo, supervisão e transparência -, o relatório conclui que, na ausência de diretrizes estratégicas, a análise da supervisão ficou prejudicada, pois se caracteriza como mecanismo que "envolve o papel do Centro de Governo de garantir que as açôes implementadas para o enfrentamento da pandemia priorizem os objetivos estabelecidos no plano estratégico, a fim de garantir a eficácia das ações". ${ }^{24}$ Já quanto ao mecanismo da coordenação, a equipe não propóe encaminhamentos tendo em vista a falta de acesso a documentos solicitados. Por último, com relação à análise da transparência, ressaltou-se a ausência de um plano de comunicação das açôes de enfrentamento da pandemia. A relatoria complementa o relatório com a constatação de que inexiste, integrados às equipes de ambos os comitês, profissionais da área da saúde que possam contribuir com uma visão técnica, salientando ainda o fato de que cargos-chave do MS "não vêm sendo ocupados por profissionais com essa formação específica" ${ }^{25}$

Por último, e náo menos importante, uma vez que se trata de analisar a efetividade de medidas e açóes para a fronteira, cabe mencionar o papel das instâncias existentes junto ao Ministério de Desenvolvimento Regional (MDR) em relação aos estados, como a Comissão Permanente para o Desenvolvimento e a Integração da Faixa de Fronteira (CDIF) e os núcleos de fronteira (NFs), respectivamente, discutindo e revelando os desafios das cidades ao enfrentamento de uma pandemia sob a perspectiva da realidade fronteiriça.

22. Disponivel em: $<$ https://bit.ly/35dA6BJ $>$.

23. Disponivel em: $<$ https:///bit.ly/35dA6BJ>.

24. Disponivel em: $<$ https://bit.ly/35dA6BJ>.

25. Disponivel em: <https://bit.ly/35dA6BJ>. 


\section{A PROPAGAÇÃO DA PANDEMIA NO BRASIL}

\subsection{Evolução dos casos e óbitos em três recortes do território}

A entrada do novo coronavírus em território brasileiro se deu passando por postos de fiscalização em aeroportos e portos internacionais da fronteira litorânea, localizados nos grandes centros e metrópoles. Em solo brasileiro, espalhou-se nessas grandes concentrações populacionais, mas não demorou a alcançar municípios de menor porte e povoados da FFT. Seus vetores espaciais de propagação associam-se a meios de deslocamento aéreos, rodoviários e fluviais, podem ser barrados por medidas de controle, higiene e distanciamento social, e a infecção que provocam é fundamentalmente socorrida pelo SUS, público e com atendimento universalizado.

O primeiro caso foi oficializado em 26 de fevereiro, e o primeiro óbito, em 17 de março, ambos em São Paulo. Em poucos meses, uma sequência de casos e óbitos confirmados como causados pela Covid-19 levaram o Brasil a ultrapassar a cifra de 1 milhăo de incidências ( 19 de junho) e 50 mil mortes ( 20 de junho). Além desses, ocultam-se sub-registros das ocorrências, contaminaçóes assintomáticas e um elevado número de internamentos e óbitos por síndrome respiratória aguda grave (SRAG), ${ }^{26}$ que embora apresentem sintomas similares aos da Covid-19, por falta ou demora nos resultados de testagem, não são registrados nessa causa de mortalidade. Como visto nas seçóes anteriores, em sua trajetória pelo Brasil o novo coronavírus encontrou diferentes possibilidades de propagação ou contenção, e provocou diferentes impactos.

Logo no início de março, as concentraçóes populacionais da FFL do Sudeste, primeiras a sentirem o peso da ameaça do novo coronavírus, implementaram medidas de controle, eficazes por um período. As concentraçóes do Nordeste e do Norte, destinos sequenciais, fizeram o mesmo, mas os efeitos agudizaram-se naquelas com menor efetividade no isolamento e distanciamento social e provocaram mais óbitos nas que contavam com serviços de saúde mais frágeis em equipamentos e recursos humanos, ou mais concentrados nas cidades principais de grandes regiôes de influência. O vírus também se mostrou ameaçador no Distrito Federal, onde se expandiu o foco de contaminação. Das grandes concentraçóes, a propagação avançou pelo sistema fluvial amazônico, por meios de transporte com elevada densidade de passageiros, infectando povoados ribeirinhos sem infraestrutura de saúde, com limitaçôes de acesso aos centros com a oferta de procedimentos de média e alta complexidade, e atingiu populaçóes com baixa ou nenhuma imunidade, como os povos indígenas.

26. Tendo como fontes InfoGripe, Fundação Oswaldo Cruz (Fiocruz), OpenDataSUS e MS, com dados notificados até a primeira semana de junho, Rossi e Buono (2020) informam que para cada 10 pessoas que morreram por Covid-19 no Brasil, outras 8 entraram na estatística das mortes por SRAG sem causa determinada. Até a primeira semana de junho, foram 23 mil casos, com sintomas similares aos da Covid-19, sendo a faixa etária de maior incidência a com 60 anos ou mais. Informam também que a elevação do número de casos acompanhando a propagação da Covid-19 (a partir da oitava semana do ano) foi equivalente a treze vezes a média dos cinco anos anteriores no mesmo período. 
Paralelamente, a partir da região adensada da FFL, a propagação avançou pelo sistema viário principal até o interior do território, acomodando-se em centros regionais e municípios industrializados, fundamentalmente das UFs do Sudeste e do Sul, e no entorno do eixo Brasília-Goiânia (figura 1). Alcançou as demais regiôes da FFT, os arranjos transfronteiriços e começou a se difundir pelo sistema viário secundário. Nessa etapa, cidades do Sul e do Centro-Oeste, que não haviam registrado números elevados de casos, por terem praticado rígidas medidas de controle, passaram a experimentar maior flexibilização da atividade econômica, o que elevou a circulaçáo de pessoas e deslocou para essas regióes os problemas de colapso do sistema de saúde já enfrentados nas demais regiōes do país. ${ }^{27}$

FIGURA 1

Brasil: trajetória da propagação do novo coronavírus no território entre 29 de fevereiro e 15 de junho de 2020

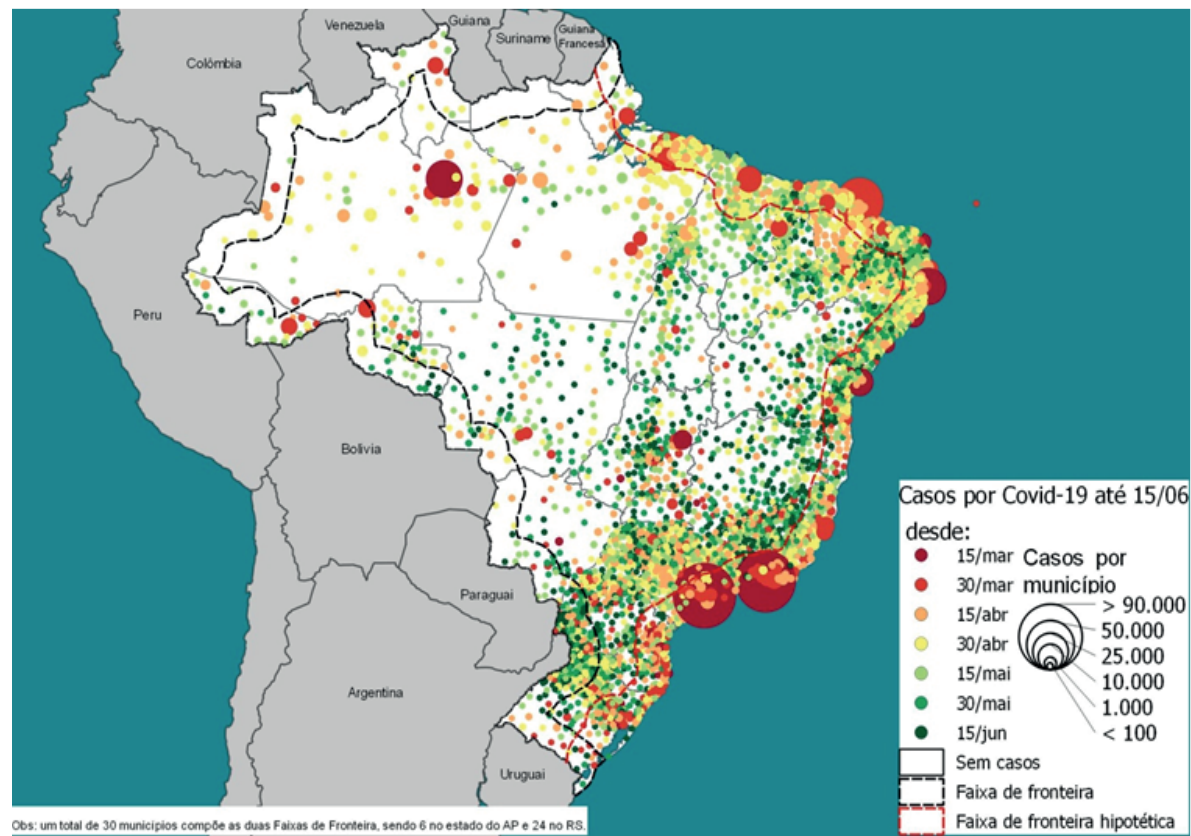

Fonte: MonitoraCovid-19, disponivel em: <https://bigdata-covid19.icict.fiocruz.br>.

Elaboração dos autores.

Obs.: Figura cujos leiaute e textos não puderam ser padronizados e revisados em virtude das condições técnicas dos originais (nota do Editorial).

27. Para sumarizar essa trajetória da propagação do Sars-COV-2 no Brasil foram considerados dados da Fiocruz, em recortes quinzenais referentes ao período compreendido entre 29 de fevereiro e 15 de junho de 2020. Dados disponíveis em: <https://bigdata-covid19.icict.fiocruz.br/>. Para a aquisição e o tratamento dos dados foi utilizada a linguagem de programação Python, e para a confecção de todos os produtos cartográficos, o software de licença aberta QGIS. 
Considerando os dados oficiais que subsidiaram essa leitura, sistematizados em períodos quinzenais, em 15 de junho de 2020, último período analisado, o Brasil registrava 4.632 municípios com casos confirmados, que somavam 886.301 casos e 44.043 óbitos por Covid-19 (tabela 2). ${ }^{28}$ Os casos e óbitos se concentravam na FFL, embora houvesse um maior número de municípios com registros entre aqueles não incluídos nas faixas de fronteira. Ao se considerar os coeficientes de incidência, as faixas de fronteira litorânea e terrestre se equiparavam com mais 5 mil casos por 1 milhão de habitantes; os coeficientes de mortalidade, novamente apontaram o resultado mais trágico na FFL - aproximadamente 300 óbitos por 1 milhão de habitantes.

TABELA 2

Brasil: casos, óbitos, e coeficientes de incidência e mortalidade por Covid-19, segundo recortes espaciais em 15 de junho de 2020

\begin{tabular}{|c|c|c|c|c|}
\hline Variável & $\mathrm{FFL}$ & FFT & Demais municípios & Total em municípios com casos \\
\hline Municípios & 1.891 & 450 & 2.291 & 4.632 \\
\hline $\begin{array}{l}\text { População (em 2019) dos } \\
\text { municípios com casos confirmados }\end{array}$ & 120.984 .821 & 10.989 .605 & 72.416 .984 & 204.391.410 \\
\hline Total de casos & 625.394 & 55.026 & 205.881 & 886.301 \\
\hline $\begin{array}{l}\text { Coeficiente de incidência } \\
\text { (casos por } 1 \text { milhão de habitantes) }\end{array}$ & $5.169,19$ & $5.007,10$ & $2.842,99$ & $4.336,29$ \\
\hline Total de óbitos confirmados & 36.145 & 1.305 & 6.593 & 44.043 \\
\hline $\begin{array}{l}\text { Coeficiente de mortalidade } \\
\text { (óbitos por } 1 \text { milhão de habitantes) }\end{array}$ & 298,76 & 118,75 & 91,04 & 215,48 \\
\hline
\end{tabular}

Fonte: MonitoraCovid-19, disponivel em: <https://bigdata-covid19.icict.fiocruz.br>

Elaboração dos autores.

Obs.: Trinta municípios dos estados do Amapá e do Rio Grande do Sul se inserem concomitantemente na FFT e FFL, mas para efeitos deste trabalho foram considerados apenas na FFT, por ser instituída em lei.

Examinando os três recortes de análise, observa-se que a curva de ascendência dos casos confirmados tem uma elevação suave no período de 29 de fevereiro a 30 de abril. A partir de então torna-se exponencial até 15 de junho, sem sinais de achatamento. Esse comportamento é determinado pelo conjunto de municípios da FFL, enquanto, no conjunto da FFT e entre os demais municípios a ascensão se torna mais elevada após 15 de maio (gráfico 1). O volume de óbitos tem supremacia na FFL, e apresenta elevação suave até 15 de junho na FFT e demais municípios, particularmente na primeira.

28. Os dados foram organizados em três recortes espaciais: $i$ ) faixa de fronteira litorânea (FFL), estimada hipoteticamente em 150 km a partir da linha da costa, compreendendo 2.067 municípios; ii) FFT, estabelecida pela Lei oㅡ6.634/1979, compreendendo 586 municípios situados ou parcialmente cortados por uma faixa de $150 \mathrm{~km}$ a partir da linha de fronteira com os países vizinhos; e iii) demais municípios brasileiros, situados entre as duas faixas de fronteira. 


\section{GRÁFICO 1}

Evolução do número de casos e de óbitos por Covid-19, segundo recortes espaciais entre 29 de fevereiro e 15 de junho de 2020

$1 \mathrm{~A}$ - Número de casos

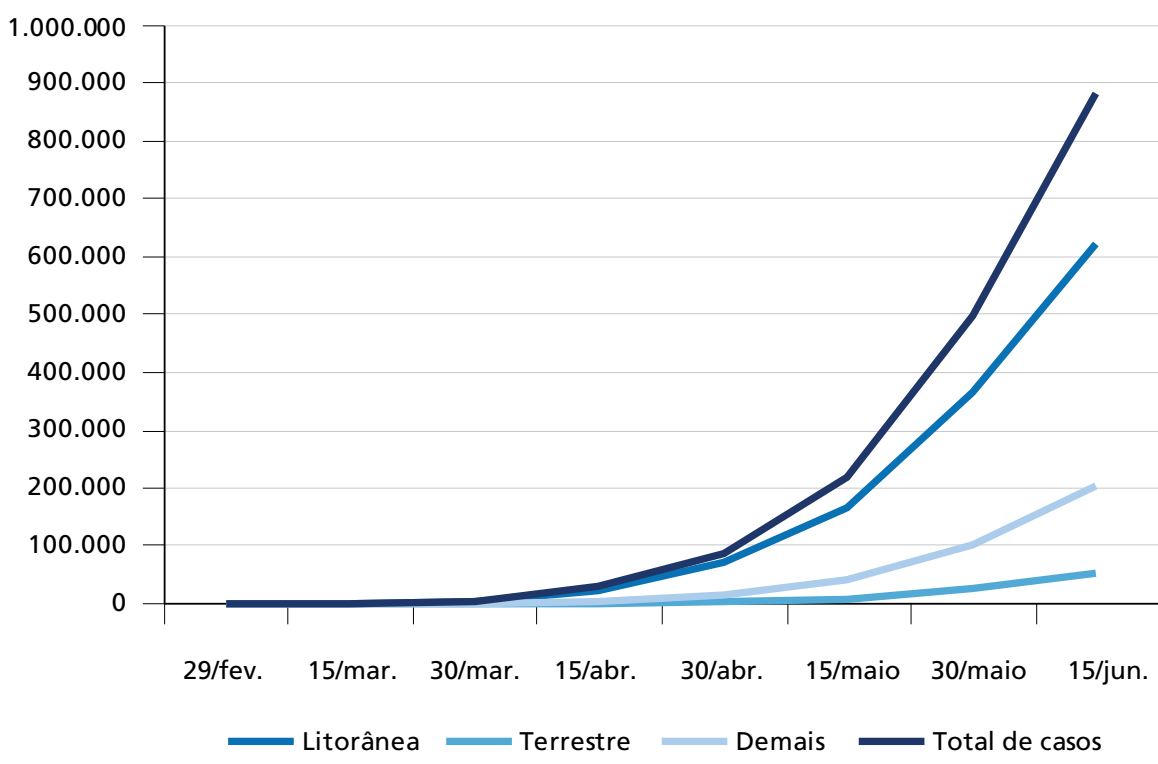

1B - Número de óbitos

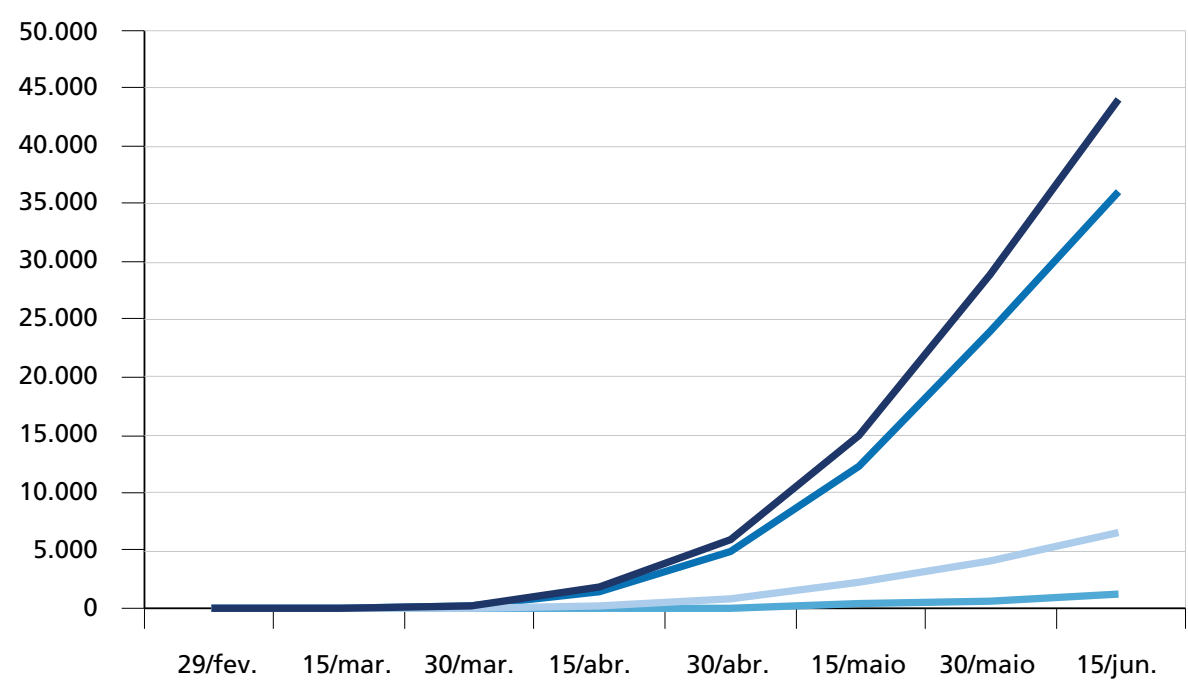

Litorânea Terrestre Demais Total de óbitos

Fonte: MonitoraCovid-19, disponível em: <https://bigdata-covid19.icict.fiocruz.br>.

Elaboração dos autores. 
$\mathrm{Na}$ evolução dos coeficientes de incidência por 1 milhão de habitantes, as faixas de fronteira litorânea e terrestre já superavam os 1 mil casos em 15 de maio e em um mês já ultrapassaram os 5 mil (gráfico 2). Os demais municípios passaram a superar mil casos por 1 milhão de habitantes no final de maio e mantêm-se em crescimento, ultrapassando o 2,8 mil em meados de junho. Também segue em intensa elevação o coeficiente de mortalidade, particularmente na FFL, desde 15 de abril, quando passou de 14,9 para 105,6 óbitos por 1 milhão de habitantes em 15 de maio, aproximando-se de 300 em 15 de junho. A FFT e os demais municípios elevaram similarmente esse coeficiente, a primeira superando os 100 e os demais aproximando-se desse coeficiente no último período.

GRÁFICO 2

Evolução dos coeficientes de incidência e mortalidade por Covid-19, segundo recortes espaciais em 15 de junho de 2020

2A - Casos por 1 milhão de habitantes

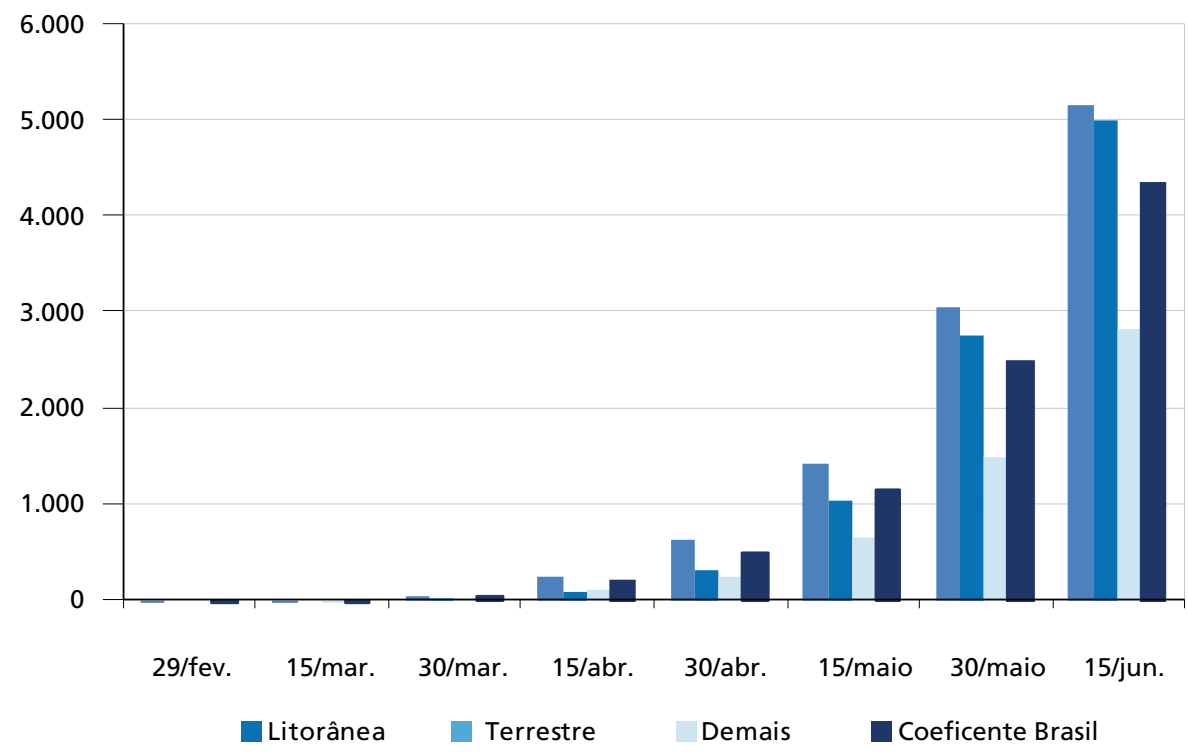




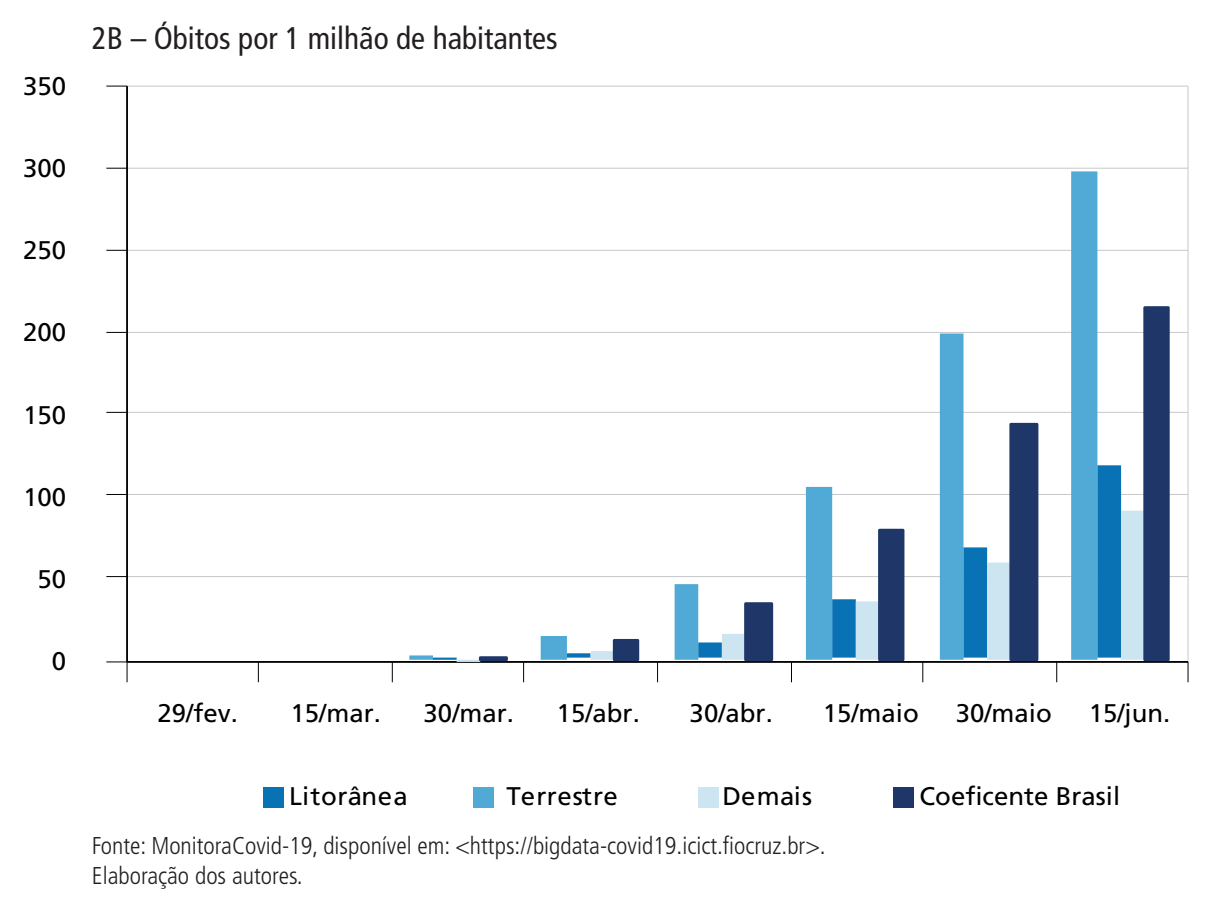

Embora deva ser considerado que o número absoluto de casos é determinante na capacidade instalada para atendimento aos infectados, podendo colocar em xeque o número de leitos, particularmente com UTIs, respiradores mecânicos e pessoal especializado nesse tipo de atendimento. Também devem causar preocupação os coeficientes elevados em municípios pequenos, desprovidos de tal especialidade, muitos situados em regiôes nas quais é grande a distância entre os centros locais e os centros regionais com tal provisão, o que dificulta ou até inviabiliza o atendimento. $\mathrm{O}$ mapeamento dos coeficientes do último período analisado demonstra que as regiôes que apresentam maiores incidência e mortalidade relativas são as faixas de fronteira litorânea, terrestre e o eixo fluvial amazônico (figura 2). Porém, o acompanhamento dos dados, logo após a segunda metade de junho, já aponta o avanço da pandemia nos estados do Sul, entre os demais municípios de todas as grandes regiôes, com uma notória tendência à agudização de contágios em municípios que desenvolvem atividades na indústria de alimentos, particularmente no processamento de carnes. 


\section{FIGURA 2}

Distribuição dos coeficientes de incidência e mortalidade por Covid-19, segundo recortes em 15 de junho de 2020
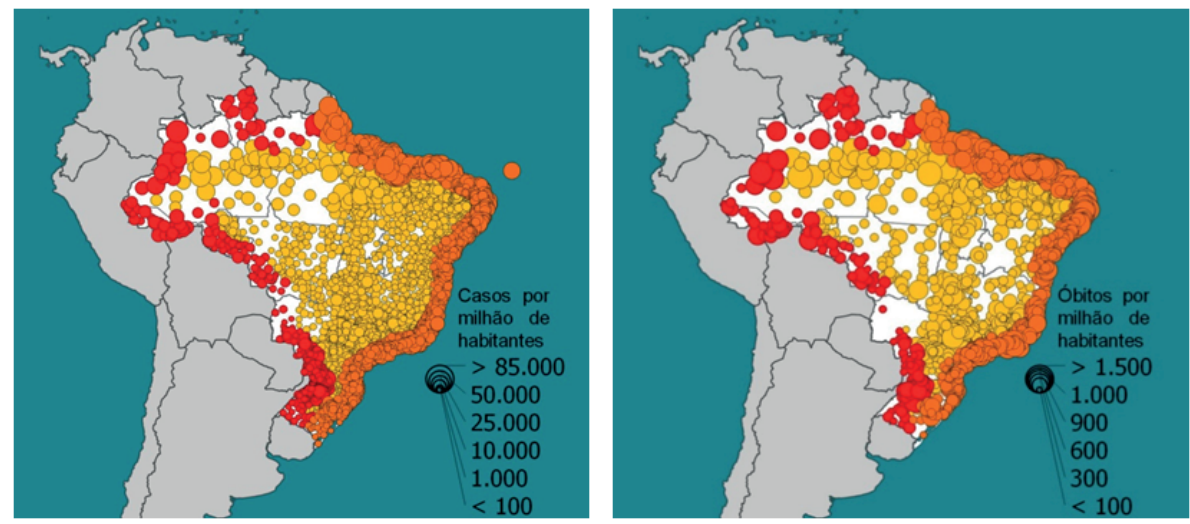

Fonte: MonitoraCovid-19, disponivel em: <https://bigdata-covid19.icict.fiocruz.br>.

Elaboração dos autores.

Obs.: Figura cujos leiaute e textos não puderam ser padronizados e revisados em virtude das condições técnicas dos originais (nota do Editorial).

\subsection{Especificidades sobre a pandemia nas faixas de fronteira}

\subsubsection{FFL}

Concentração, adensamento, multiplicidade e multidirecionalidade de fluxos e muitas pessoas (vetores) em movimento: essas são as peculiaridades da FFL. As grandes concentraçōes urbanas dessa faixa caracterizam-se ainda pela presença de centralidades com equipamentos sanitários e serviços de alta complexidade, em contraste com áreas desprovidas de saneamento básico, serviços essenciais de saúde e moradia adequados. ${ }^{29}$

Com a propagação da Covid-19 em larga escala nessa região, a explosão concomitante de casos logo levou à saturação da oferta de leitos e serviços especializados, colocando em colapso o sistema de saúde em algumas metrópoles, confirmando a baixa capacidade de atendimento em situaçôes de emergência. Para que o SUS garantisse cobertura a toda a população que depende da atenção pela saúde pública, o sistema mereceria reforço e redistribuição de equipamentos, recursos humanos e medicamentos (particularmente anestésicos e sedativos para o processo de intubação), além de adotar medidas coordenadas nacionalmente para

29. A FFL possui 2.067 municípios, nos quais residem 58,5\% da população do país. Segundo o IBGE (2019), registram-se vinte áreas de grande concentração de população, configurando arranjos espaciais com população superior a 750 mil habitantes, em manchas contínuas de ocupação urbana, a maioria no entorno de capitais de UFs. Além de elevado movimento pendular de pessoas para estudo e/ou trabalho entre seus municípios, situam-se nessa faixa as principais infraestruturas de conectividade internas e externas ao país, como aeroportos de categoria internacional, portos organizados e uma densa rede de rodovias federais e estaduais. 
estancar a propagação da Covid-19, mantendo severo controle sobre a relação demanda/oferta de leitos, principalmente com UTIs e respiradores mecânicos.

No Brasil, essa coordenação nacional se fez por um curto espaço de tempo, aproximadamente até meados de abril. Nesse período, a evolução do processo de contaminação se manteve sob controle, com medidas de distanciamento social, suspensão de atividades não essenciais, e ampla orientação aos entes federados e à população quanto a protocolos internacionais e procedimentos para conter um desastre iminente. Até então, as curvas ascendiam sem grande intensidade, mas se temia que, ao alcançar as áreas pobres nas periferias urbanas, o vírus encontrasse ambiente propício à propagação: domicílios com adensamento de moradores, esgotos a céu aberto e falta de água para a higiene mínima das mãos. De fato, o novo coronavírus entrou nas cidades, em suas áreas nobres, pelos vetores de viajantes das classes média e alta, mas se difundiu nas periferias urbanas, pelos prestadores precários de serviços, entregadores delivery e trabalhadores dos serviços essenciais, que não pararam para a quarentena, muitos sem acesso ao suporte emergencial de renda para garantia da sobrevivência.

Passado abril, sem uma ação de contingência emergencial para a pandemia, coordenada em nível nacional e com a participação ativa dos estados e municípios, sob orientação de especialistas, e ainda com a curva em ascensão, medidas de flexibilização passaram a pontuar em estados e municípios brasileiros, o que não tardou em provocar, como mostram os números, uma proliferação exponencial dos casos e óbitos, particularmente na FFL.

\subsubsection{FFT}

$\mathrm{Na}$ FFT, onde a rede urbana é pouco densa e há grande distância entre centros, constata-se insuficiência da capacidade da rede de saúde, particularmente para atendimentos de média e alta complexidade, que se fazem presentes apenas em poucos centros de maior porte, nem sempre com vias de acesso rápido e adequado a transporte de doentes graves. Nesses centros, a rede sanitária também logo entrou em colapso.

$\mathrm{Na}$ linha de fronteira, algumas das cidades afetadas configuram arranjos transfronteiriços, que formam manchas de ocupação contínua que integram territórios de mais de um país. É comum nesses casos a prestação do atendimento à saúde pelo município mais bem estruturado, em alguns casos do lado brasileiro, em outros, no país vizinho. Porém, com a pandemia, o fechamento sumário das fronteiras desconsiderou essa especificidade, e criou obstáculos para uma população cujas relaçóes sociais e econômicas transcendem a demarcação fronteiriça.

Muitos dos arranjos transfronteiriços passaram a apresentar casos da Covid-19 e também de óbitos, em coeficientes muito elevados (tabela 3). 
Os arranjos do arco Norte reúnem um elevado número de casos, óbitos e coeficientes de incidência e mortalidade por 1 milháo de habitantes - todos em grau muito superior aos coeficientes da FFT (5.007 para incidência e 105,6 para mortalidade). Tabatinga, na fronteira com a Colômbia, registra o maior número de casos e de óbitos entre os municípios que integram arranjos transfronteiriços, superando 1,1 mil casos que já culminaram em 67 óbitos. Nos outros arcos fronteiriços, apenas Guajará-Mirim, no arco Central, apresenta coeficientes de incidência e mortalidade superiores aos da FFT, enquanto Dionísio Cerqueira, no arco Sul, supera no de mortalidade,

TABELA 3

Arranjos transfronteiriços com incidência da Covid-19 em 15 de junho de 2020

\begin{tabular}{|c|c|c|c|c|c|}
\hline UF & Município/outros municípios do arranjo & $\begin{array}{l}\text { Casos em } \\
15 \text { de junho }\end{array}$ & $\begin{array}{l}\text { Óbitos em } \\
15 \text { de junho }\end{array}$ & $\begin{array}{c}\text { Coeficiente de } \\
\text { incidência } \\
\text { (por } 1 \text { milhão } \\
\text { de habitantes) }\end{array}$ & $\begin{array}{c}\text { Coeficiente de } \\
\text { mortalidade } \\
\text { (por } 1 \text { milhão } \\
\text { de habitantes) }\end{array}$ \\
\hline \multicolumn{6}{|l|}{ Arco Norte } \\
\hline Acre & Assis Brasil/Bolpebra (Bolívia)/Iñapari (Peru) & 95 & 5 & $12.808,41$ & 674,12 \\
\hline Acre & Brasiléia, Epitaciolândia/Cobija (Bolívia) & 213 & 6 & $8.105,64$ & 228,32 \\
\hline Acre & Epitaciolândia & 119 & 4 & $6.463,52$ & 217,26 \\
\hline Acre & Santa Rosa do Purus/Puerto Esperanza (Peru) & 79 & 1 & $12.079,51$ & 152,90 \\
\hline Amazonas & Tabatinga/Letícia (Colômbia)/Santa Rosa (Peru) & 1.180 & 67 & $17.921,15$ & $1.017,55$ \\
\hline Amapá & Oiapoque/St. Georges (Guiana Francesa) & 927 & 7 & $33.993,40$ & 256,69 \\
\hline Roraima & Bonfim/Lethem (Guiana) & 107 & 5 & $8.622,77$ & 402,93 \\
\hline Roraima & Pacaraima/Santa Elena de Uairén (Venezuela) & 251 & 8 & $14.424,46$ & 459,74 \\
\hline \multicolumn{6}{|l|}{ Arco Central } \\
\hline Rondônia & Guajará-Mirim/Guayaramerín (Bolívia) & 689 & 32 & $14.921,82$ & 693,03 \\
\hline Mato Grosso & Cáceres/San Matías (Bolívia) & 68 & 5 & 720,52 & 52,97 \\
\hline Mato Grosso do Sul & Bela Vista/Bella Vista del Norte (Paraguai) & 2 & 0 & 81,20 & 0,00 \\
\hline Mato Grosso do Sul & $\begin{array}{l}\text { Corumbá, Ladário/Puerto Quijarro, Puerto } \\
\text { Suarez (Bolívia) }\end{array}$ & 140 & 2 & $1.256,33$ & 17,94 \\
\hline Mato Grosso do Sul & Ladário & 21 & 0 & 900,09 & 0,00 \\
\hline Mato Grosso do Sul & Paranhos/Ypejhú (Paraguai) & 1 & 0 & 70,28 & 0,00 \\
\hline Mato Grosso do Sul & $\begin{array}{l}\text { Ponta Porã/Pedro Juan Caballero, Zanja } \\
\text { Pytá (Paraguai)' }\end{array}$ & 59 & 1 & 637,65 & 10,80 \\
\hline Mato Grosso do Sul & Mundo Novo & 17 & 0 & 925,62 & 0,00 \\
\hline
\end{tabular}




\begin{tabular}{|c|c|c|c|c|c|}
\hline UF & Município/outros municípios do arranjo & $\begin{array}{l}\text { Casos em } \\
15 \text { de junho } 1\end{array}$ & $\begin{array}{l}\text { Óbitos em } \\
15 \text { de junho }\end{array}$ & $\begin{array}{l}\text { Coeficiente de } \\
\text { incidência } \\
\text { (por } 1 \text { milhão } \\
\text { de habitantes) }\end{array}$ & $\begin{array}{l}\text { Coeficiente de } \\
\text { mortalidade } \\
\text { (por } 1 \text { milhão } \\
\text { de habitantes) }\end{array}$ \\
\hline \multicolumn{6}{|l|}{ Arco Sul } \\
\hline Paraná & $\begin{array}{l}\text { Guaíra (Paraná), Mundo Novo (Mato Grosso do } \\
\text { Sul)/Salto del Guairá (Paraguai) }\end{array}$ & 15 & 3 & 452,91 & 90,58 \\
\hline Paraná & $\begin{array}{l}\text { Foz do Iguaçu, Santa Terezinha de Itaipu/Ciudad del } \\
\text { Este, Hernandarias, Minga Guazú, Presidente Franco } \\
\text { (Paraguai)/Puerto Iguazú (Argentina) }\end{array}$ & 168 & 4 & 649,82 & 15,47 \\
\hline Paraná & Santa Terezinha de Itaipu & 30 & 0 & $1.278,5$ & 0,00 \\
\hline Paraná & $\begin{array}{l}\text { Santo Antônio do Sudoeste, Pranchita'/San } \\
\text { Antonio (Argentina) }\end{array}$ & 1 & 0 & 49,58 & 0,00 \\
\hline Paraná & Barracão & 6 & 0 & 583,94 & 0,00 \\
\hline Paraná & Bom Jesus do Sul & 3 & 0 & 847,21 & 0,00 \\
\hline Santa Catarina & $\begin{array}{l}\text { Dionísio Cerqueira, Barracão, Bom Jesus do Sul/ } \\
\text { Bernardo de Irigoyen (Argentina) }\end{array}$ & 5 & 2 & 322,62 & 129,04 \\
\hline Rio Grande do Sul & Itaqui/Alvear (Argentina) & 4 & 0 & 106,32 & 0,00 \\
\hline Rio Grande do Sul & Porto Mauá/Alba Posse (Argentina) & 1 & 0 & 421,23 & 0,00 \\
\hline Rio Grande do Sul & Porto Xavier/San Javier (Argentina) & 21 & 0 & $2.049,58$ & 0,00 \\
\hline Rio Grande do Sul & Quaraí/Artigas (Uruguai) & 15 & 2 & 661,17 & 88,15 \\
\hline Rio Grande do Sul & Sant'Ana do Livramento/Rivera (Uruguai) & 65 & 1 & 843,85 & 12,98 \\
\hline Rio Grande do Sul & São Borja/Santo Tomé (Argentina) & 17 & 0 & 282,01 & 0,00 \\
\hline Rio Grande do Sul & Uruguaiana/Paso de los Libres (Argentina) & 61 & 0 & 480,42 & 0,00 \\
\hline Rio Grande do Sul & Bagé $^{2}$ & 75 & 0 & 619,10 & 0,00 \\
\hline
\end{tabular}

Fonte: MonitoraCovid-19, disponivel em: <https://bigdata-covid19.icict.fiocruz.br>.

Elaboração dos autores.

Notas: ${ }^{1}$ Não apresentou casos no período.

${ }^{2}$ Integra o arranjo transfronteiriço de Aceguá (Rio Grande do Sul), sem casos registrados, e Acegua, no Uruguai.

Outros municípios da linha de fronteira, que se encontram em análise para confirmar sua condição de arranjo transfronteiriço, registram números absolutos de casos e óbitos e coeficientes ainda mais expressivos. No arco Norte, é o caso de municípios do Acre na fronteira com Bolívia, como Plácido de Castro (arranjo espacial com Villa Evo Morales) e Capixaba (com Villa Bella), assim como Acrelândia; do Amazonas, na fronteira com Peru, como Benjamin Constant (com Islandia) e Atalaia do Norte; e na fronteira com a Colômbia, como Santo Antônio do Içá (com Tarapaca), Japurá (arranjo com La Pedrera) e São Gabriel da Cachoeira (com Yavarate), este também com distrito na fronteira com a Venezuela. Outros casos de elevados registros ocorrem em municípios da linha de fronteira do arco Central com Bolívia, em Rondônia, precisamente Pimenteiras do Oeste; e do arco Sul com Argentina, no Rio Grande do Sul, como em Esperança do Sul e em Tiradentes do Sul, este compondo provável arranjo com El Soberbo. 
Importante ressaltar que os municípios citados e localizados no arco Norte servem de apoio na oferta de serviços à população dos países limítrofes, e a incidência e a mortalidade registradas refletem a precariedade da infraestrutura em saúde da região. Algumas UFs, considerando a contaminação em cidade transfronteiriça do país vizinho, tomaram medidas antecipadas - como no caso do fechamento do ponto de fronteira do Brasil com a Guiana Francesa, solicitado pelo governo do Amapá. Os demais países tomaram medidas próprias quanto ao fechamento da fronteira, e no momento em análise temem a reabertura devido ao avanço da pandemia no Brasil, como tratado na seção 2 .

Deve-se considerar que o fechamento dos pontos de fronteira terrestre tem a implicação territorial de separar as manchas de ocupação contínua entre países, formadas pelos arranjos transfronteiriços (ou "cidades gêmeas", como comumente tratados), impedindo relacionamentos vitais à dinâmica desses espaços e de seus moradores. Entre as dificuldades criadas à população, estão fundamentalmente as restriçóes aos movimentos pendulares, cujos fluxos concretizam a interação entre os lados da fronteira quanto ao exercício do trabalho, consumo, acesso a serviços, entre outras atividades rotineiras à vida em qualquer cidade. Neles, a dimensão transfronteiriça constitui uma instância para a qual a mobilidade é uma condição imprescindível a sua existência socioespacial. Em alguns arranjos, particularmente perpassados por fronteiras secas, informaçóes pontuais relatam acordos entre os poderes públicos locais na gestão do problema transfronteiriço, empreendendo esforços para manter aberto o diálogo com o país vizinho e diminuir os impactos na vida cotidiana. Os problemas agravados pela pandemia da Covid-19 colocam em relevo a necessidade de se buscar alternativas de barreiras de controle fronteiriço fora dos limites do espaço urbano edificado que sejam dotadas de serviços de acolhimento e orientação aos que fazem a travessia.

Outro problema peculiar à FFT, particularmente na Amazônia Legal, são os inúmeros povoados em que vivem segmentos vulneráveis de população, como ribeirinhos, extrativistas, indígenas, além de aldeias de povos indígenas ainda em completo isolamento (figura 3). A atenção a esses povos, com baixa ou nenhuma imunidade para se protegerem da contaminação, esbarra nas dificuldades de acesso para tratamento a doentes e para a prestação de serviço de orientação e procedimentos preventivos à infecção. A situação se agrava diante da sua vulnerabilidade física ao contágio, da exposição ante a chegada de equipes de saúde externas e do isolamento e da distância dos centros urbanos onde estáo os locais de atendimento.

Instituiçôes como a Fundação Nacional do Índio (Funai), a Secretaria Especial de Saúde Indígena (Sesai) e o MS manifestaram preocupação quanto aos povos indígenas, recomendando a adoção de medidas restritivas à entrada de pessoas em todos os territórios indígenas, reforçadas as restriçōes de acesso aos 
habitados por povos isolados ${ }^{30}$ ou de recente contato, incluindo a necessidade de quarentena para profissionais de saúde e membros da Funai, antes do acesso a esses povos (Brasil, 2020). Tais instituições preveem também a vulnerabilidade dessas populações às doenças respiratórias, o que aumenta o risco de agravamento em caso de contágio pelo novo coronavírus.

\section{FIGURA 3}

\section{Amazônia Legal: terras indígenas próximas a municípios com contágio da Covid-19}

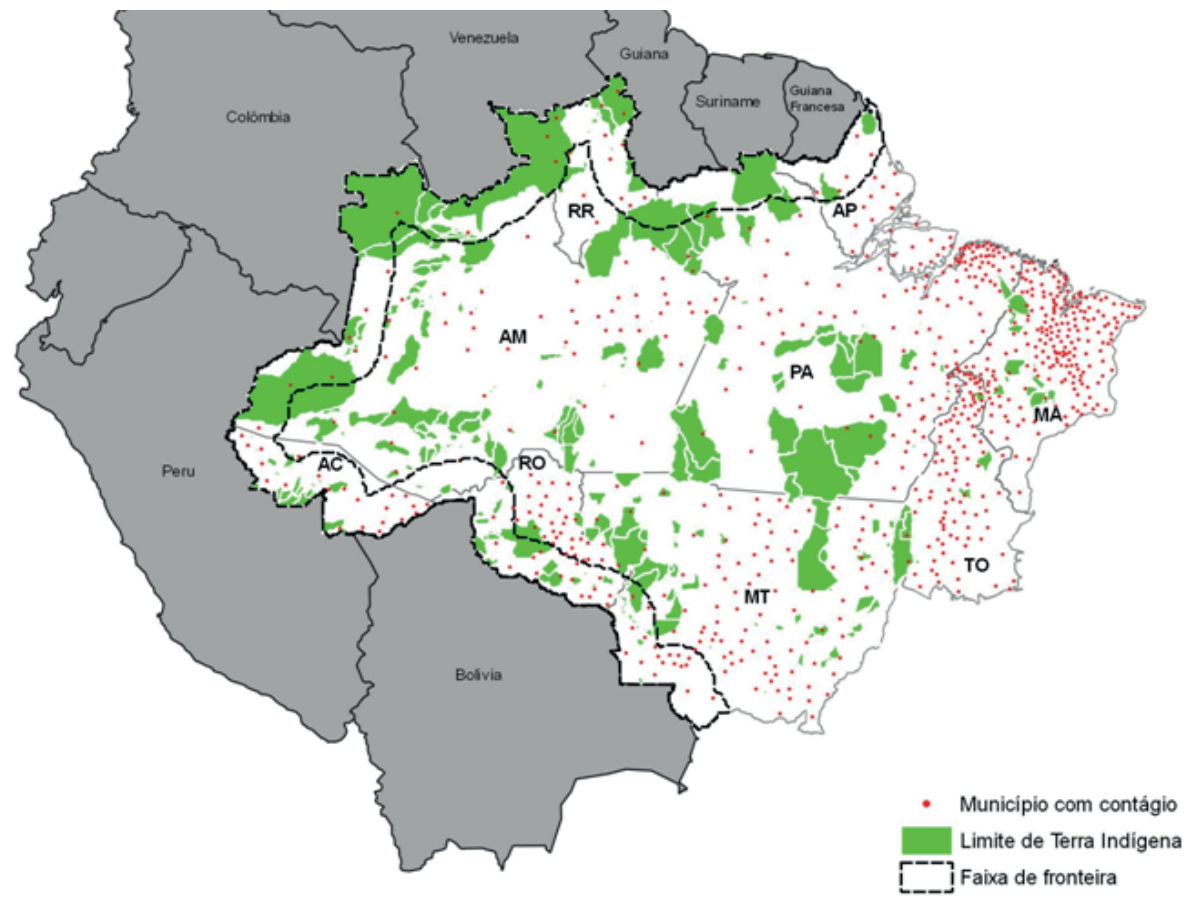

Fonte: MonitoraCovid-19, disponível em: <https://bigdata-covid19.icict.fiocruz.br>; e Funai, 2019, disponível em: <http:// mapas2.funai.gov.br/portal_mapas/pdf/terra_indigena.pdf>.

\section{Elaboração dos autores.}

Obs.: Figura cujos leiaute e textos não puderam ser padronizados e revisados em virtude das condições técnicas dos originais (nota do Editorial).

É importante considerar que se somam a essa fragilidade do sistema imunológico dos indígenas, principalmente os que não tiveram contato com populaçâo não indígena, a aproximaçấo de garimpeiros ilegais, grileiros e madeireiros às suas terras, e muitas medidas de desregramento ambiental têm sido implementadas sem nenhum diálogo, aproveitando o momento em que a quarentena e a propagação e os efeitos da Covid-19 ocupam a atenção da mídia.

30. De acordo com relatório elaborado pelo Conselho de Direitos Humanos da Organização das Nações, refere-se especificamente a grupos indígenas com ausência de relações permanentes com a sociedade ou com pouca frequência de interação, seja com não índios, seja com outros povos indígenas (UNHRC, 2020). 
Segundo dados da "Plataforma de monitoramento da situação indígena na pandemia do novo coronavírus (Covid-19) no Brasil", em função da subnotificação dos casos indígenas pelos dados oficiais, a Articulação dos Povos Indígenas no Brasil (APIB) vem realizando um levantamento independente dos casos, chegando a números superiores aos notificados pela Sesai, que tem contabilizado somente casos em terras indígenas homologadas. ${ }^{31}$ Em 26 de junho, o número de casos confirmados entre os indígenas brasileiros era de 8.115, com registro de 347 óbitos e 104 povos afetados. ${ }^{32}$ Vale lembrar que das 185 terras indígenas situadas na FFT, 34 possuem parte de seus limites na linha de fronteira, e há 45 povos indígenas que vivem compartilhadamente em território brasileiro e em território de países vizinhos ${ }^{33}$ o que torna a atenção a esses povos uma questão binacional, tão difícil de ser equacionada, ou até mais, que a gestâo urbana dos arranjos transfronteiriços.

Em suma, as questóes delineadas tratam, por um lado, da desmistificação sobre a Amazônia isolada e preservada na medida em que se revelam uma grande quantidade de tribos e grupos indígenas, estes sim definidos como povos isolados; muitas dessas tribos encontram-se contaminadas ou em perigo de contaminaçáo por mineradores e exploradores de madeira (ISA, 2020). ${ }^{34}$ Contudo, ressalta-se que o aparente desgoverno com relação às medidas federais para o enfretamento da pandemia, não é verificado com relação ao desenvolvimento do agronegócio nesse período: não somente o PIB desse setor cresceu (FEALQ, CNA e CEPEA, 2020) ${ }^{35}$ como também, conforme indicado em dados do Sistema de Alerta de Desmatamento (SAD) e do DETER, houve um grande aumento do desmatamento na Amazônia Legal, indicando a pressão pelo seu avanço. Resultados apresentados em relatório de 17 de junho, elaborado por um conjunto de organizaçóes da sociedade civil, a partir de dados comparados do sistema de alerta de agosto de 2019 a abril de 2020 com agosto de 2018 a abril de $2019,{ }^{36}$ as entidades afirmam que "o desmatamento em 2020 será ainda maior que em 2019, ano em que o Brasil registrou a maior taxa de desmatamento na Amazônia dos últimos 10 anos" (Greenpeace et al., 2020). De acordo com a análise realizada, "entre agosto

31. A compilação de dados da APIB tem sido feita pelo Comitê Nacional de Vida e Memória Indígena e pelas organizações indígenas de base da APIB, para o que utiliza diferentes fontes de dados, que incluem dados da Sesai, das secretarias municipais e estaduais de saúde e do Ministério Público Federal (MPF).

32. Mais informações disponíveis em: <https://covid19.socioambiental.org/>

33. Mais informações disponíveis em: <https://pib.socioambiental.org/pt/Povos_ind\%C3\%ADgenas_e_soberania_nacional> 34. Em documento que denuncia o impacto da pandemia na terra de grupos indígenas isolados yanomamis (vasta área localizada na faixa de fronteira) e que gerou o manifesto \#foragarimpoforacovid, declara-se que os garimpeiros (20 mil garimpeiros ilegais) são o principal vetor do novo coronavírus dentro do território yanomami, cujo levantamento para o estudo considerou 13.889 indígenas (50,7\% da população da terra indígena yanomami), e demonstrou que, se nada for feito, 5.600 indígenas poderão ser infectados. Soma-se ao impacto a alta vulnerabilidade desses povos a doenças. 35. 0 produto interno bruto (PIB) do agronegócio brasileiro registrou alta, pelo terceiro mês consecutivo (FEALQ, CNA e CEPEA, 2020).

36. Relatório de abaixo-assinado onde firmam o ISA, Imaflora, Rede Xingu, Instituto do Homem e Meio Ambiente da Amazônia (Imazon), Instituto Interacional de Educação do Brasil (IEB) e o Greenpeace, informando os resultados da análise realizada ao MPF, Ministério Público do Estado do Pará, ao Conselho Nacional do Ministério Público e ao governo do estado do Pará (Greenpeace et al., 2020). 
de 2019 e abril de 2020, as áreas de alerta de desmatamento detectadas pelo sistema SAD/Imazon somaram 391.800 hectares na Amazônia Legal, que revela uma tendência de aumento de $81 \%$ em relação ao período de agosto de 2018 a abril de 2019 ". ${ }^{37}$

\section{CONSIDERAÇÕES FINAIS}

A trajetória aqui descrita demonstra que de fato a pandemia é um problema fronteiriço, e que como medida inicial é fundamental evitar o acesso das epidemias nos países ou regióes. Para tal, por vezes, se exige fechamento completo ou parcial, mas sob controle, de seus portóes de entrada. Contudo, uma vez que essa medida é tomada, a experiência brasileira desde que fechou suas fronteiras, há três meses, mostrou que, seja nas grandes concentraçóes populacionais da fronteira litorânea, seja nos arranjos transfronteiriços da fronteira terrestre, a rede urbana aponta para cidades que exigem ser administradas por inúmeras esferas de governo, de forma a assumir funçōes públicas de interesse comum, apoiadas em articulaçôes e açôes plurimunicipais, sob pactos federativos entre estados e açóes de cooperação com os países vizinhos.

É preciso também colocar nas agendas públicas a valorização do SUS, com uma equipamentação abrangente da rede de saúde nas grandes aglomeraçóes ou nos pequenos centros mais distantes, para possíveis novos eventos pandêmicos, seja uma segunda onda, seja uma terceira onda do próprio novo coronavírus, levando em conta suas mutaçóes ou outros contaminantes.

E, além de tudo, para essas funções, faz-se necessário um governo determinado a assumir o seu papel diante de situaçôes transversais ao já atribulado cotidiano de gestão de um país que tem no aprofundamento das desigualdades o seu principal desafio. Seguindo a análise de acompanhamento da gestáo para o enfrentamento da Covid-19 organizada pelo TCU, com estrutura e capacidade mínima de "estratégia, coordenação, supervisão e transparência" para uma adequada governança, as necessidades das regióes de fronteira devem ser combatidas a partir de açóes que contemplem: $i$ ) a criação de um comitê de acompanhamento da crise do vírus no qual se integre a CDIF, em articulação com os núcleos estaduais de fronteira; ii) a criação de um protocolo de enfrentamento de crises, respeitando as características e especificidades das fronteiras terrestre e litorânea; iii) a implementação de medidas em articulação com os países vizinhos, estados e municípios fronteiriços; iv) a previsão de recursos e medidas de alerta para a implantação de hospitais de campanha, em capitais de estados e cidades gêmeas (arranjos transfronteiriços); $v$ ) o desenvolvimento de protocolos para rápida fiscalizaçáo e o controle em aeroportos e portos; e vi) o desenvolvimento de mecanismos de obrigatoriedade para o funcionamento efetivo da necessária articulação entre os entes federados em tempos de pandemia.

37. Outro estudo chega a resultados semelhantes, concluindo que "a taxa de desmatamento entre agosto de 2019 e 14 de maio de 2020 já representa 89\% da área desmatada no ano anterior" (Aragão et al., 2020). 
Com as fronteiras físicas fechadas no Brasil, o avanço da doença coloca em relevo conflitos em curso que avançam de fronteira a fronteira, evidenciando o agravo da situação em grande contingente de diversas populaçôes vulneráveis entre favelados, sem-teto, informais, índios, quilombolas ou reassentados, cuja visibilidade apresenta-se, a depender da perspectiva que se toma para analisá-la, como uma janela de oportunidades.

Seexisteaoportunidade de rever processos para um novocurso dedesenvolvimento das ações em políticas públicas, então devem ser destinados recursos para enfrentar os ambientes propícios a futuras pandemias, quais sejam, os mesmos ambientes também vulneráveis a outros eventos globais: revertendo os processos legais que têm levado à devastação e ao desmatamento sem precedentes na Amazônia; suprindo a ausência do saneamento básico, com universalização da oferta de água tratada nas torneiras das moradias, de tratamento de esgotos, coleta e destino adequado aos resíduos urbanos; além de intensificar programas para a oferta de moradia adequada que atendam e ofereçam condiçóes saudáveis ao crescente segmento de população que se adensa em cômodos precários e insalubres nas tantas favelas e ocupaçóes que se tornarão ainda maiores, dado o previsível aumento da pobreza, do desemprego, e da ausência completa de renda nos tempos seguintes à atual pandemia.

\section{REFERÊNCIAS}

ARAGÃO, L. E. O. C.; SILVA JUNIOR, C. H. L.; ANDERSON, L. O. O desafio do Brasil para conter o desmatamento e as queimadas na Amazônia durante a pandemia por COVID-19 em 2020: implicaçôes ambientais, sociais e sua governança. São José dos Campos: INPE, 2020. Disponível em: <https:// www.socioambiental.org/sites/blog.socioambiental.org/files/nsa/arquivos/ dematamento_fogo_covid19_aragao_et_al.pdf>.

BEL, P. P. Coronavírus: por que o Peru não consegue conter a covid-19, apesar de quarentena e investimentos. BBC News Brasil, 25 maio 2020. Disponível em: <https://www.bbc.com/portuguese/internacional-52796852>. Acesso em: 29 jun. 2020.

BENITES, A.; GORTÁZAR, N. G. Mandetta, o conservador que vestiu o colete do SUS e entrincheirou Bolsonaro. El País, 5 abr. 2020. Disponível em: <https:// brasil.elpais.com/brasil/2020-04-04/mandetta-o-conservador-que-vestiu-ocolete-do-sus-e-entrincheirou-bolsonaro.html>. Acesso em: 29/06/2020.

BRASIL. Decreto no 10.282, de 20 de março de 2020. Regulamenta a Lei no 13.979, de 6 de fevereiro de 2020, para definir os serviços públicos e as atividades essenciais. Diário Oficial da Uniáo, 20 mar. 2020. Disponível em: <http://www.planalto.gov.br/ccivil_03/_ato2019-2022/2020/decreto/D10282. htm>. Acesso: 29 de jun. 2020. 
CANCIAN, N.; URIBE, G. Compra em massa pelos EUA cancelou aquisição de equipamentos para o Brasil, diz Mandetta. Folha de Sáo Paulo, 1ํ abr. 2020. Disponível em: <https://www1.folha.uol.com.br/equilibrioesaude/2020/04/ compra-em-massa-pelos-eua-cancelou-compras-de-equipamentos-para-o-brasildiz-mandetta.shtml>. Acesso em: 29 jun. 2020.

COE-COVID19 - CENTRO DE OPERAÇÓES DE EMERGÊNCIA EM SAÚDE PÚBLICA. Boletim epidemiológico, n. 6, 3 abr. 2020. Disponível em: $<$ https://portalarquivos.saude.gov.br/images/pdf/2020/April/03/BE6-BoletimEspecial-do-COE.pdf>. Acesso em: 16 abr. 2020.

DELATORRE, E. et al. Tracking the onset date of the community spread of SARSCoV-2 in Western Countries. Memórias do Instituto Oswaldo Cruz, Rio de Janeiro, v. 115, 2020. Disponível em: <https://www.scielo.br/scielo. php?script=sci_arttext\&pid=S0074-02762020000100415>.

FEALQ - FUNDAÇÃO DE ESTUDOS AGRÁRIOS LUIZ DE QUEIROZ; CNA - CONFEDERAÇÃO DA AGRICULTURA E PECUÁRIA DO BRASIL; CEPEA - CENTRO DE ESTUDOS AVANÇADOS EM ECONOMIA APLICADA. PIB do agronegócio cresce em março e acumula alta de 3,3\% no primeiro trimestre. São Paulo: FEALQ; CNA; CEPEA, 2020. Disponível em: <https://www.cepea.esalq.usp.br/upload/kceditor/files/Cepea_PIB_Agro_ marco_junho2020(1).pdf>. Acesso em: 29 jun. 2020.

GOMES, F. A. R. Isolamento horizontal versus isolamento vertical no combate à Covid-19. Jornal da USP, 13 abr. 2020. Disponível em: <https://jornal.usp. br/artigos/isolamento-horizontal-versus-isolamento-vertical-no-combate-acovid-19/>. Acesso em: 29 jun. 2020.

GREENPEACE et al. Informa resultados científicos de análises de desmatamento na Amazônia Legal e ocorrência de crimes ambientais em áreas críticas, solicitando a adoçáo de providências urgentes. Belém: [s.n.], 17 jun. 2020. Disponível em: <https://www.socioambiental.org/sites/blog.socioambiental. org/files/nsa/arquivos/representacao_deter_sad_sirad17jun2020.pdf>. Acesso em: 29 jun. 2020.

IBGE - INSTITUTO BRASILEIRO DE GEOGRAFIA E ESTATÍSTICA. Estimativas da populaçáo residente no Brasil e unidades da federaçáo com data de referência em 1o de julho de 2019. Rio de Janeiro: IBGE; Copis; ME, 2019.

ISA - INSTITUTO SOCIOAMBIENTAL. O impacto da pandemia na terra indígena yanomami. São Paulo: ISA, 2020. Disponível em: <https://acervo. socioambiental.org/acervo/publicacoes-isa/o-impacto-da-pandemia-na-terraindigena-yanomami-foragarimpoforacovid>. Acesso em: 29 jun. 2020. 
MALDONADO, C. S.; GÜELL, O. OMS alerta que a pandemia do coronavírus "se acelera" e agora seu epicentro está na América. El País, 19 jun. 2020. Disponível em: <https://brasil.elpais.com/sociedade/2020-06-19/oms-alertaque-a-pandemia-do-coronavirus-se-acelera-e-agora-seu-epicentro-esta-naamerica.html>. Acesso em: 29 jun. 2020.

MENDONÇA, H.; MOLINA, F. R. Epicentro da covid-19 na América do Sul, Brasil é visto como "grande ameaça" por países vizinhos. El País, 12 maio 2020. Disponível em: <https://brasil.elpais.com/brasil/2020-05-12/epicentro-da-covid19-na-america-do-sul-brasil-e-visto-como-grande-ameaca-por-paises-vizinhos. html\#?sma=newsletter_brasil_diaria20200513>. Acesso em: 26 jun. 2020.

PÊGO, B. et al. Pandemia e fronteiras brasileiras: análise a evolução da Covid-19 e proposições. Ipea: Brasília, 2020. (Nota Técnica, n 16). Disponível em: <https:// www.ipea.gov.br/portal/images/stories/PDFs/nota_tecnica/200521_n_16_dirur. pdf>. Acesso em: 26 jun. 2020.

ROSSI, A.; BUONO, R. As mortes incógnitas da pandemia. Piauí, 15 jun. 2020. Disponível em: <https://piaui.folha.uol.com.br/as-mortes-incognitas-dapandemia/?utm_campaign=a_semana_na_piaui_10\&utm_medium=email\&utm_ source $=\mathrm{RD}+$ Station $>$. Acesso em: 26 jun. 2020.

SOUZA, R. et al. Uso da cloroquina no tratamento da Covid-19 provocou saída de Teich. Correio Braziliense, 15 maio 2020. Disponível em: <https:// www.correiobraziliense.com.br/app/noticia/politica/2020/05/16/interna_ politica,855426/uso-da-cloroquina-no-tratamento-da-covid-19-provocou-saidade-teich.shtml>. Acesso em: 29 jun. 2020.

SPERB, P. Preocupado, presidente do Uruguai reforça barreiras sanitárias com Brasil. Folha de S.Paulo, 25 maio 2020. Disponível em: <https://www1.folha. uol.com.br/mundo/2020/05/preocupado-com-covid-19-presidente-do-uruguaivisita-fronteira-com-brasil.shtml>. Acesso em: 26 jun. 2020.

UNHRC - UNITED NATIONS HUMAN RIGHTS COUNCIL. Ameaças e violaçáo de direitos humanos no Brasil: povos indígenas isolados. Brasília: UNHCR, mar. 2020. Disponível em: <https://www.socioambiental.org/ sites/blog.socioambiental.org/files/arquivos/povos_isolados_cdh_onu_ relatorio_2020.pdf>. Acesso em: 29 jun. 2020.

VERDÉLIO, A. Ministério da Saúde muda formato de divulgação de dados de covid-19. Agência Brasil, 8 jun. 2020. Disponível em: <https://agenciabrasil. ebc.com.br/saude/noticia/2020-06/ministerio-da-saude-muda-formato-dedivulgacao-de-dados-de-covid-19>. Acesso em: 29 jun. 2020. 
